\title{
Biological Treatments: New Weapons in the Management of Monogenic Autoinflammatory Disorders
}

\author{
Antonio Vitale, ${ }^{1}$ Donato Rigante, ${ }^{2}$ Orso Maria Lucherini, ${ }^{1}$ Francesco Caso, ${ }^{3}$ \\ Isabella Muscari, ${ }^{1}$ Flora Magnotti, ${ }^{1}$ Maria Giuseppina Brizi, ${ }^{1}$ Susanna Guerrini, ${ }^{1}$ \\ Maria Patti, ${ }^{2}$ Leonardo Punzi, ${ }^{3}$ Mauro Galeazzi, ${ }^{1}$ and Luca Cantarini ${ }^{1}$ \\ ${ }^{1}$ Research Center of Systemic Autoimmune and Autoinflammatory Diseases, Rheumatology Unit, Policlinico Le Scotte, \\ University of Siena, Viale Bracci 1, 53100 Siena, Italy \\ ${ }^{2}$ Institute of Pediatrics, Università Cattolica Sacro Cuore, Policlinico A. Gemelli, Largo A. Gemelli 8, 00168 Rome, Italy \\ ${ }^{3}$ Rheumatology Unit, Department of Clinical and Experimental Medicine, University of Padova, Via Giustiniani 2, 35128 Padova, Italy
}

Correspondence should be addressed to Luca Cantarini; cantariniluca@hotmail.com

Received 1 April 2013; Accepted 27 May 2013

Academic Editor: Hermann Gram

Copyright (C) 2013 Antonio Vitale et al. This is an open access article distributed under the Creative Commons Attribution License, which permits unrestricted use, distribution, and reproduction in any medium, provided the original work is properly cited.

\begin{abstract}
Treatment of monogenic autoinflammatory disorders, an expanding group of hereditary diseases characterized by apparently unprovoked recurrent episodes of inflammation, without high-titre autoantibodies or antigen-specific $\mathrm{T}$ cells, has been revolutionized by the discovery that several of these conditions are caused by mutations in proteins involved in the mechanisms of innate immune response, including components of the inflammasome, cytokine receptors, receptor antagonists, and oversecretion of a network of proinflammatory molecules. Aim of this review is to synthesize the current experience and the most recent evidences about the therapeutic approach with biologic drugs in pediatric and adult patients with monogenic autoinflammatory disorders.
\end{abstract}

\section{Introduction}

Monogenic autoinflammatory disorders (AIDs) are a recently identified group of hereditary diseases characterized by apparently unprovoked recurrent febrile episodes associated with inflammatory symptoms affecting a host of organs and systems, most often the skin, serous membranes, musculoskeletal apparatus, gastrointestinal tube, eyes, and/or nervous system [1-16]. Differently from the chapter of autoimmune diseases, in monogenic AIDs, the recurrent febrile and inflammatory episodes occur in the absence of autoantibodies or antigen-specific and autoreactive T lymphocytes [17]. Their pathogenesis is mostly related to the presence of mutations in genes encoding proteins involved in the innate immune system regulation or in inflammatory response adjustment, resulting in an immense production of proinflammatory cytokines, in particular interleukin- (IL-) 1 [18].

At a clinical point of view, monogenic AIDs are characterized by considerable heterogeneity in terms of age of onset, frequency and intensity of attacks, clinical manifestations, or responsiveness to treatment, probably due to the wide range of mutations involved in different genes [13-16]. Monogenic AIDs-related mutations can have high penetrance, often generating a more aggressive phenotype, or low penetrance, often underlying a less severe clinical picture with a later onset, lower frequency of attacks, and atypical or paucisymptomatic phenotypes. Therefore, the identification of patients carrying low-penetrance mutations may be problematical, and in these cases there are relevant criticalities in establishing a correct differential diagnosis [19-25]. Our increasing understanding of the molecular mechanisms involved in monogenic AIDs has recently opened new intriguing sceneries in terms of treatment, which should be initiated as early as possible to avoid systemic secondary amyloidosis, which is considered the most dreadful complication of monogenic AIDs, occurring in up to $25 \%$ of overlooked patients [26, 27].

Aim of this review is to synthesize the current experience and evidences about this ever-new therapeutic approach in monogenic AIDs. 


\section{Classification of the Monogenic Autoinflammatory Disorders}

Systemic hereditary monogenic AIDs (see Table 1) include familial Mediterranean fever (FMF), tumor necrosis factor receptor-associated periodic syndrome (TRAPS), the family of cryopyrin-associated periodic syndromes (CAPS), which in turn include familial cold urticaria syndrome (FCAS), Muckle-Wells syndrome (MWS), and neonatal onset multisystem inflammatory disease (NOMID, also named "chronic infantile neurological cutaneous and articular syndrome" or CINCA syndrome), mevalonate kinase deficiency syndrome (MKD), also known in the past as "hyper-gammaglobulinemia D syndrome", NLRP12-associated autoinflammatory disorder (NLRP12AD), a granulomatous disorder with familial presentation called Blau syndrome (BS), and, finally, hereditary pyogenic disorders, which include Majeed syndrome (MS), PAPA (pyogenic arthritis, pyoderma gangrenosum, and acne) syndrome (PAPAs), and IL-1 receptor antagonist deficiency (DIRA). Some of these-namely FMF, MKD, MS, and DIRA - are transmitted by autosomal recessive inheritance, while the others-TRAPS, FCAS, MWS, NOMID, NLRP12AD, BS, and PAPAs - are autosomal dominant. The genes associated with monogenic AIDs have been identified in recent years and, with the exception of MKD, which is caused by the deficiency of mevalonate kinase, the second enzyme of mevalonate/isoprenoid pathway, encode for proteins involved in the activity of inflammasome, a multiprotein complex which activates the processing and secretion of IL- $1 \beta$ and different other cytokines with proinflammatory effects [28]. In addition, MKD is characterized by a $1-8 \%$ residual enzymatic activity, while the complete lack of this enzyme causes a distinct metabolic syndrome, called mevalonic aciduria (MA) [29].

\section{Cornerstones of Treatment in Monogenic Autoinflammatory Disorders}

The main three objectives of therapy for patients with monogenic AIDs are (i) controlling symptoms, (ii) improving patient's quality of life, and (iii) preventing long-term complications. For years, treatment has been symptomatic, based on the sole utilization of nonsteroidal anti-inflammatory drugs (NSAIDs), high-dose corticosteroids, colchicine, or immunomodulators. With the exception of colchicine in FMF, these treatments often fail to provide an adequate control of symptoms and inflammation indexes, in particular serum amyloid-A (SAA), which must be kept within a normal range as the product of its cleavage accumulates progressively in various tissues, giving rise to systemic amyloidosis [30-32]. In general, any treatment should be adapted to maintain SAA concentration within the reference range, and any treatment that fails to guarantee the suppression of SAA levels is to be considered insufficient and must be changed [32].

Recently, the introduction of biological pharmaceutical agents has revolutionized the approach to monogenic AIDs, in particular for CAPS and TRAPS, while for FMF, colchicine is still the mainstay of therapy, resulting efficacious in 90$95 \%$ of patients $[30,31]$. Mechanisms of IL-1, tumor necrosis factor (TNF)- $\alpha$, and interleukin-6 (IL-6) targeted therapies are shown in Figure 1. Obviously, the most appropriate treatment for monogenic AIDs must be tailored to the single patient, based on the severity of his/her clinical phenotype, which can vary greatly $[33,34]$. In addition, any treatment efficacy should be evaluated on the basis of routinary control of inflammatory parameters, SAA and proteinuria, to test and treat an eventual subclinical and latent inflammation. The recent and ongoing clinical trials on biologic treatments in the monogenic AIDs are listed in Table 2.

\section{Familial Mediterranean Fever (FMF)}

The mainstay of FMF therapy continues to be colchicine, for its ability to control recurrent attacks as well as to prevent amyloidosis, which is the major long-term ominous complication of FMF [35, 36]. In some cases, proteinuria due to amyloidosis disappears while treatment with colchicine [37]. The initial colchicine dose is $1 \mathrm{mg} / \mathrm{day}$, which may be slowly increased up to $2.5 \mathrm{mg}$ /day in cases of partial response, but in children colchicine dosage can also be calculated based on body weight or body surface area [38]. Recently, a webbased registry in which clinical information on anonymized patients with monogenic AIDs was collected retrospectively as part of the Eurofever initiative (EAHC Project no. 2007332) indicated that 121 patients with FMF received colchicine: 75 (62\%) experienced a complete response, 44 (36\%) a partial response, and 2 failed to respond [34]. This confirms that true nonresponders to colchicine are very rare and should be distinguished from patients treated with insufficient dosages or those with poor compliance. In fact, compliance is hampered by the frequent occurrence of side effects, particularly at the gastrointestinal level, which sometimes induce patients to abandon colchicine $[39,40]$. Corticosteroids seem to be effective in decreasing attack symptoms and pain, while NSAIDs attenuate clinical signs and generally fail to prevent relapses, though they can act as simple analgesics during attacks [41, 42].

Although the role of TNF- $\alpha$ in the pathogenesis of FMF is not yet well defined, over the past decade many patients with FMF have been treated with anti-TNF agents. At present, three TNF- $\alpha$ antagonists are in use: etanercept, a fusion protein of the TNF receptor and the Fc region of human $\operatorname{IgG}_{1}$, infliximab, a chimeric anti-TNF monoclonal antibody, and adalimumab, a fully humanized monoclonal antibody against human TNF- $\alpha$. To date, etanercept is the most used anti-TNF agent in FMF patients, followed by infliximab. In most cases, anti-TNF agents can control FMF attacks quite effectively, improving clinical manifestations and acute phase response [43-51]. In such cases anti-TNF agents led to the improvement of proteinuria in those patients with a secondary amyloidosis: 2 out of 8 patients with FMF-related amyloidosis treated with infliximab have showed complete resolution of proteinuria, or proteinuria improvement in the others as well, suggesting a possible role in the control of renal disease outcome [47-51]. Loss of efficacy for colchicine was described 
TABLE 1: Basic genetic and clinical keys of the monogenic autoinflammatory disorders discussed in the review.

\begin{tabular}{|c|c|c|c|c|}
\hline Disease & $\begin{array}{c}\text { Gene } \\
\text { (Locus) }\end{array}$ & Protein & Inheritance & Prominent clinical features or potential complications \\
\hline FMF & $\begin{array}{l}M E F V \\
(16 \mathrm{p} 13.3)\end{array}$ & Pyrin & $\mathrm{AR}$ & $\begin{array}{l}\text { Recurrent fever, serositis (abdominal and chest pain), } \\
\text { arthralgias or arthritides, erysipelas-like skin eruption on } \\
\text { the legs, good response to colchicine, and amyloidosis in } \\
\text { untreated, resistant, and noncompliant patients }\end{array}$ \\
\hline TRAPS & $\begin{array}{l}\text { TNFRSF1A } \\
\quad(12 \mathrm{p} 13)\end{array}$ & $\begin{array}{l}\text { Tumor necrosis } \\
\text { factor receptor } 1\end{array}$ & $\mathrm{AD}$ & $\begin{array}{l}\text { Recurrent fever, migrating muscle and joint involvement, } \\
\text { abdominal pain, serosal inflammatory involvement, steroid } \\
\text { responsiveness of febrile attacks, conjunctivitis, periorbital } \\
\text { edema, and amyloidosis }\end{array}$ \\
\hline FCAS & & & & $\begin{array}{l}\text { Recurrent fever, and cold-induced urticaria-like rash, } \\
\text { conjunctivitis, arthralgias }\end{array}$ \\
\hline MWS & $\begin{array}{r}N L R P 3 \\
(1 \mathrm{q} 44)\end{array}$ & Cryopyrin & $\mathrm{AD}$ & $\begin{array}{l}\text { Recurrent fever, urticaria-like rash, conjunctivitis, } \\
\text { arthralgias, sensorineuroal deafness, and amyloidosis }\end{array}$ \\
\hline NOMID & & & & $\begin{array}{l}\text { Subcontinuous fever, chronic urticaria-like rash, uveitis, } \\
\text { papilledema, deforming arthritides involving large joints } \\
\text { (knees), aseptic chronic meningopathy, sensorineuroal } \\
\text { deafness, and amyloidosis }\end{array}$ \\
\hline MKD & $\begin{array}{l}M V K \\
(12 \mathrm{q} 24)\end{array}$ & Mevalonate kinase & $\mathrm{AR}$ & $\begin{array}{l}\text { Recurrent fever, polymorphous rash, arthralgias, abdominal } \\
\text { pain, diarrhea, lymph node enlargement, headache, } \\
\text { splenomegaly, oral and genital aphthosis, and high rate of } \\
\text { self-resolution during adulthood }\end{array}$ \\
\hline NLRP12AD & $\begin{array}{r}\text { NLRP12 } \\
(19 \mathrm{q} 13)\end{array}$ & Monarch-1 & $\mathrm{AD}$ & $\begin{array}{l}\text { Recurrent fever after cold exposure, arthralgias, and } \\
\text { cold-induced urticaria-like rash }\end{array}$ \\
\hline BS & $\begin{array}{l}\text { NOD2 } \\
(C A R D 15) \\
(16 q 12.1-13)\end{array}$ & NOD2 & $\mathrm{AD}$ & $\begin{array}{l}\text { Intermittent fever, granulomatous dermatitis with } \\
\text { ichthyosis-like changes, granulomatous polyarthritis, } \\
\text { recurrent panuveitis, and onset before } 5 \text { years }\end{array}$ \\
\hline MS & $\begin{array}{l}\text { LPIN2 } \\
(18 \mathrm{p} 11.31)\end{array}$ & Lipin 2 & $\mathrm{AR}$ & $\begin{array}{l}\text { Recurrent multifocal osteomyelitis, dyserythropoietic } \\
\text { anemia, and chronic dermatosis }\end{array}$ \\
\hline PAPAs & $\begin{array}{c}\text { PSTPIP1 } \\
(15 \mathrm{q} 24-\mathrm{q} 25.1)\end{array}$ & $\begin{array}{l}\qquad \mathrm{CD}_{2} \\
\text { antigen-binding } \\
\text { protein } 1\end{array}$ & $\mathrm{AD}$ & $\begin{array}{l}\text { Pyoderma gangrenosum, cystic acne, and sterile pyogenic } \\
\text { oligoarthritis }\end{array}$ \\
\hline DIRA & $\begin{array}{r}I L 1 R N \\
(2 \mathrm{q} 14)\end{array}$ & $\begin{array}{l}\text { Interleukin-1 } \\
\text { receptor antagonist }\end{array}$ & $\mathrm{AR}$ & $\begin{array}{l}\text { Neonatal onset-multifocal osteomyelitis, periostitis, } \\
\text { neonatal onset-pustular rash, and dramatic response to } \\
\text { anakinra }\end{array}$ \\
\hline
\end{tabular}

FMF: familial Mediterranean fever; TRAPS: tumor necrosis factor receptor-associated periodic syndrome; FCAS: familial cold autoinflammatory syndrome; MWS: Muckle-Wells syndrome; NOMID: neonatal onset multisystem inflammatory disease; MKD: mevalonate kinase deficiency syndrome; NLRP12AD: NLRP12-associated autoinflammatory disorder; BS: Blau syndrome; MS: Majeed syndrome; PAPAs: pyogenic arthritis, pyoderma gangrenosum, acne syndrome; DIRA: deficiency of interleukin-1 receptor antagonist; AR: autosomal recessive; AD: autosomal dominant.

in a 25 -year-old woman, which was then treated with infliximab and then with etanercept, who had lost responsiveness to infliximab probably for the production of neutralizing anti-infliximab antibodies [52]. In other cases, anti-TNF agents have brought only a partial benefit, and resolution of symptoms was noted with anti-IL-1 agents [53]. In line with this finding, Ozen et al. reported the effect of anti-TNF therapy (etanercept) and anti-IL-1 treatment (anakinra) in 6 cases resistant to colchicine. Although etanercept lowered the number of attacks (from 3-4 attacks per month to 2 attacks per month), attacks still recurred and acute-phase reactants remained high in 2 patients; thus etanercept was considered ineffective and all patients were switched to anakinra [54]. On the basis of these cases, however, anti-TNF agents seem to be an option for patients with FMF who are unresponsive or intolerant to colchicine therapy and might have a promising role in the treatment of FMF-associated amyloidosis [55].

Recently, in agreement with the more recent studies about the pathogenetic origin of FMF, given that high levels of IL- $1 \beta$ (and NF- $\kappa \mathrm{B}$ ) were considered responsible for most disease manifestations, IL-1 inhibitors, such as anakinra, a competitive IL-1 receptor antagonist, canakinumab, a fully humanized $\operatorname{IgG}_{1}$ monoclonal antibody specifically acting against IL-1 $\beta$, and rilonacept, a dimeric glycoprotein consisting of human IL-1 receptor extracellular domains and the Fc portion of human $\operatorname{IgG}_{1}$, have been effective in colchicine-resistant patients and are actually regarded as the most valid therapeutic option for FMF patients unresponsive or intolerant to colchicine as well as those with concomitant vasculitis [56-58]. Accordingly, data from the Eurofever 


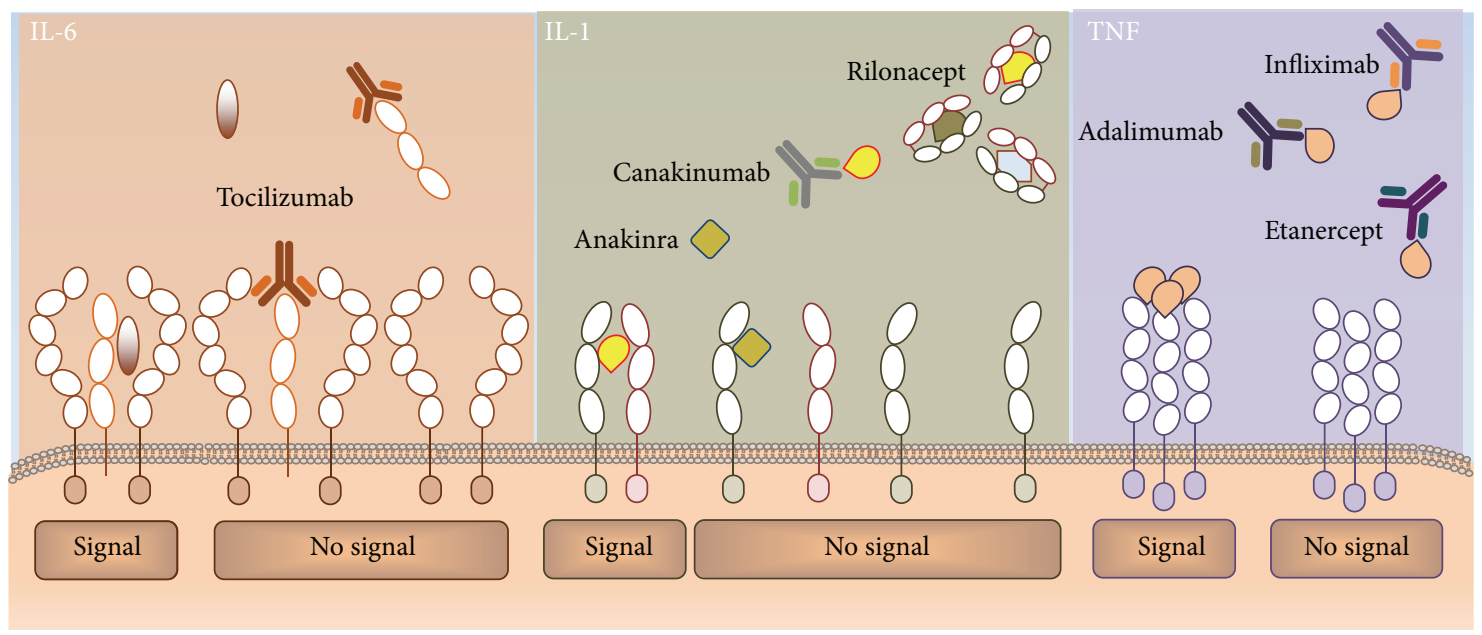

\begin{tabular}{|c|c|c|}
\hline$=g p 130$ & $\begin{array}{l}8=I L-1 R I \\
0\end{array}$ & $D=$ IL-1RA \\
\hline$=\mathrm{IL}-6 \mathrm{R}$ & $\bigcirc=\mathrm{IL}-1 \beta$ & $8=$ TNFR \\
\hline$=$ IL- 6 & $\frac{8}{0}=\mathrm{IL}-1 \mathrm{RAcP}$ & 0 \\
\hline$=$ sIL-6R & $O=\mathrm{IL}-1 \alpha$ & \\
\hline
\end{tabular}

Figure 1: Mechanisms of IL-1, IL-6, and TNF- $\alpha$ targeted therapies. Binding of IL- 6 to the IL- 6 receptor complex, involving IL-6 receptor (IL6R) and glycoprotein 130 (gp130), leads to activation of IL-6 signal transduction. Tocilizumab, a recombinant humanized anti-IL-6 receptor antibody, inhibits the binding of IL-6 to IL-6R or soluble IL-6R (sIL-6R), thus blocking IL-6 inflammatory response. Binding of IL-1 $\beta$ to the IL-1 receptor type I (IL-1RI) promotes a receptor complex formation with the IL-1 receptor accessory protein (IL-1RAcP), that results in signal transduction activation. IL-1-targeted therapy includes anakinra (IL-1R receptor antagonist), canakinumab (anti-IL-1 $\beta$ IgG1 mAb), and rilonacept (soluble IL-1 receptor that binds IL-1 $\beta$, IL-1 $\alpha$, and IL1RA). Adalimumab, infliximab, and etanercept are anti-TNF blockers. Adalimumab is a fully human monoclonal anti-TNF antibody. Infliximab is a mouse/human chimeric monoclonal anti-TNF antibody. Etanercept is a dimeric fusion protein of TNFR2 (p75) linked with the Fc region of human $\operatorname{IgG}_{1}$.

registry showed that 3 patients were treated with anakinra, with a complete response in all cases, including 1 patient who failed to respond to colchicine [34]. However, to date, the availability of case series alone and the lack of randomized and controlled studies or cohort studies give to anakinra, along with the remainder of TNF- $\alpha$ inhibitors, an evidence level " 4 " and a " $\mathrm{C}$ " recommendation strength.

In March 2013, according to a systematic search of the literature through PubMed/Medline, as many as $29 \mathrm{FMF}$ patients have been treated with anakinra, as described in 16 clinical reports published from 2006 [54, 56, 58-66]. In all cases there was a good clinical response, and anakinra led to the complete disappearance of FMF clinical manifestations and/or normalization of inflammatory markers. Moreover, even in cases of partial response, anakinra led to a significant improvement in terms of frequency of attacks and severity of clinical manifestations. Interestingly, a girl diagnosed both with FMF and Behçet's disease underwent anakinra treatment and had a completely positive clinical response (including Behçet's clinical features): however, although she was symptom-free and her acute-phase reactants remained normal, at the 18th month of treatment, proteinuria gradually increased and serum albumin levels decreased, due to likely amyloidosis which was previously established [61]. In another case, anakinra led to the stabilization of renal function in terms of glomerular filtration rate as well as of proteinuria at the 17-month follow-up visit [60].

In most cases, anakinra dosage was $1-2 \mathrm{mg} / \mathrm{kg} /$ day (for pediatric patients) or $100 \mathrm{mg} /$ day (for adult ones), though in 1 case anakinra was administered during FMF attacks, suggesting its possible on-demand employment [62]. Interestingly, in the case presented by Moser et al., the dose of anakinra had to be increased from $100 \mathrm{mg}$ three times weekly to $100 \mathrm{mg}$ daily after renal transplantation, due to the reactivation of FMF, probably related to an improved drug clearance [63]. At last, some clinicians have administered anakinra $100 \mathrm{mg}$ two or three times a week $[58,60,63]$ and also every 48 hours [58, 64-66]. The management of colchicine therapy after starting anakinra may vary greatly, with some authors reducing colchicine dosage, others maintaining the same dosage, and others discontinuing colchicine. As regards safety, skin manifestations at the site of injections were the most frequently observed side effect. However, 1 patient experienced acute interstitial pneumonia fifteen days after starting anakinra [64], and another one presented Rotavirus gastroenteritis, Haemophilus bronchitis, and a slight neutropenia, which did not require hospitalization [60]. Although hypertension is not regarded as an anakinra-related side effect, 1 patient 
TABLE 2: Recent and ongoing clinical trials on biologic treatments in the monogenic autoinflammatory disorders.

\begin{tabular}{|c|c|c|c|c|c|}
\hline & Phase & Status & Study & Disease & $\begin{array}{l}\text { ClinicalTrials.gov } \\
\text { identifier }\end{array}$ \\
\hline \multirow{4}{*}{ Anakinra } & III & $\begin{array}{l}\text { Not yet } \\
\text { recruiting }\end{array}$ & $\begin{array}{l}\text { Kineret (Anakinra) in adult patients with } \\
\text { colchicine-resistant familial Mediterranean fever }\end{array}$ & FMF & NCT01705756 \\
\hline & I & Completed & $\begin{array}{l}\text { The use of kineret (anakinra) in the treatment of } \\
\text { familial cold urticaria }\end{array}$ & FCAS & NCT00214851 \\
\hline & II & Recruiting & $\begin{array}{l}\text { Anakinra to treat patients with neonatal onset } \\
\text { multisystem inflammatory disease }\end{array}$ & NOMID & NCT00069329 \\
\hline & II & Recruiting & Anakinra for inflammatory pustular skin diseases & PAPAs & NCT01794117 \\
\hline \multirow{15}{*}{ Canakinumab } & III & Terminated & $\begin{array}{l}\text { Canakinumab to treat neonatal-onset multisystem } \\
\text { inflammatory disease }\end{array}$ & NOMID & NCT00770601 \\
\hline & III & Recruiting & $\begin{array}{l}\text { Efficacy, safety, and tolerability of ACZ885 in pediatric } \\
\text { patients with the following cryopyrin-associated } \\
\text { periodic syndromes: familial cold autoinflammatory } \\
\text { syndrome, Muckle-Wells syndrome, or neonatal onset } \\
\text { multisystem inflammatory disease }\end{array}$ & CAPS & NCT01576367 \\
\hline & III & Completed & $\begin{array}{l}\text { The safety and efficacy of canakinumab in patients aged } \\
4 \text { years or older diagnosed with cryopyrin-associated } \\
\text { periodic syndromes (CAPS) in Canada }\end{array}$ & CAPS & NCT01105507 \\
\hline & III & Completed & $\begin{array}{l}\text { Efficacy and safety study of canakinumab administered } \\
\text { for } 6 \text { months ( } 24 \text { weeks) in japanese patients with } \\
\text { cryopyrin-associated periodic syndromes followed by } \\
\text { an extension phase }\end{array}$ & CAPS & NCT00991146 \\
\hline & II & $\begin{array}{l}\text { Active, not } \\
\text { recruiting }\end{array}$ & $\begin{array}{l}\text { Evaluation of the safety and efficacy of canakinumab in } \\
\text { pediatric patients with colchicine intolerant or } \\
\text { colchicine-resistant familial Mediterranean fever (FMF) } \\
\text { (CONTROL FMF) }\end{array}$ & FMF & NCT01148797 \\
\hline & II & Completed & $\begin{array}{l}\text { Efficacy and safety, of canakinumab in patients with } \\
\text { colchicine-resistant familial Mediterranean fever }\end{array}$ & FMF & NCT01088880 \\
\hline & III & Recruiting & $\begin{array}{l}\text { Efficacy, safety and tolerability of ACZ885 in pediatric } \\
\text { patients with the following cryopyrin-associated } \\
\text { periodic syndromes: familial cold autoinflammatory } \\
\text { syndrome, Muckle-Wells syndrome, or neonatal onset } \\
\text { multisystem inflammatory disease }\end{array}$ & CAPS & NCT01302860 \\
\hline & III & $\begin{array}{l}\text { Completed } \\
\text { Has results }\end{array}$ & $\begin{array}{l}\text { Efficacy and safety of ACZ885 in patients with the } \\
\text { following cryopyrin-associated periodic syndromes: } \\
\text { familial cold autoinflammatory syndrome, } \\
\text { Muckle-Wells syndrome, or neonatal onset multisystem } \\
\text { inflammatory disease }\end{array}$ & CAPS & NCT00685373 \\
\hline & III & Terminated & $\begin{array}{l}\text { Canakinumab to treat neonatal-onset multisystem } \\
\text { inflammatory disease }\end{array}$ & NOMID & NCT00770601 \\
\hline & II & Recruiting & Canakinumab for pyoderma gangrenosum & & NCT01302795 \\
\hline & - & Recruiting & $\begin{array}{l}\text { Clinical outcomes and safety: a registry study of ilaris } \\
\text { (canakinumab) patients (B-confident) }\end{array}$ & CAPS & NCT01213641 \\
\hline & II & Recruiting & $\begin{array}{l}\text { Canakinumab in patients with active hyper-IgD } \\
\text { syndrome }\end{array}$ & MKD & NCT01303380 \\
\hline & II & Completed & $\begin{array}{l}\text { Safety, efficacy, pharmacokinetics, and } \\
\text { pharmacodynamics of ACZ885 in patients with NALP3 } \\
\text { mutations and clinical symptoms }\end{array}$ & CAPS & NCT00487708 \\
\hline & III & $\begin{array}{l}\text { Completed } \\
\text { Has results }\end{array}$ & $\begin{array}{l}\text { Efficacy, safety, and tolerability of ACZ885 in patients } \\
\text { with Muckle-Wells syndrome (REMITTER) }\end{array}$ & MWS & NCT00465985 \\
\hline & II & $\begin{array}{l}\text { Active, not } \\
\text { recruiting }\end{array}$ & $\begin{array}{l}\text { Efficacy and safety study of ACZ885 in patients with } \\
\text { active recurrent or chronic (Tumor Necrosis Factor) } \\
\text { TNF-receptor-associated periodic syndrome (TRAPS) }\end{array}$ & TRAPS & NCT01242813 \\
\hline
\end{tabular}


TABLE 2: Continued.

\begin{tabular}{|c|c|c|c|c|c|}
\hline & Phase & Status & Study & Disease & $\begin{array}{c}\text { ClinicalTrials.gov } \\
\text { identifier }\end{array}$ \\
\hline \multirow{5}{*}{ Rilonacept } & II & $\begin{array}{l}\text { Completed } \\
\text { Has results }\end{array}$ & $\begin{array}{l}\text { Rilonacept for treatment of familial Mediterranean } \\
\text { fever (FMF) }\end{array}$ & FMF & NCT00582907 \\
\hline & III & $\begin{array}{l}\text { Completed } \\
\text { Has results }\end{array}$ & $\begin{array}{l}\text { Rilonacept for treatment of cryopyrin-associated } \\
\text { periodic syndromes (CAPS) }\end{array}$ & CAPS & NCT00288704 \\
\hline & II & Completed & $\begin{array}{l}\text { Safety and tolerability of rilonacept in Muckle-Wells } \\
\text { syndrome (MWs) or Schnitzler syndrome } \\
\text { (ACCILTRA1) }\end{array}$ & MWS & NCT01045772 \\
\hline & II & Recruiting & $\begin{array}{l}\text { Rilonacept for deficiency of the interleukin-1 receptor } \\
\text { antagonist (DIRA) }\end{array}$ & DIRA & NCT01801449 \\
\hline & II & Completed & Interleukin-1 trap to treat autoinflammatory disease & $\begin{array}{l}\text { FMF, } \\
\text { CAPS }\end{array}$ & NCT00094900 \\
\hline
\end{tabular}

FMF: familial Mediterranean fever; TRAPS: tumor necrosis factor receptor-associated periodic syndrome; FCAS: familial cold autoinflammatory syndrome; MWS: Muckle-Wells syndrome; NOMID: neonatal onset multisystem inflammatory disease; MKD: mevalonate kinase deficiency syndrome; PAPAs: pyogenic arthritis, pyoderma gangrenosum, acne syndrome; DIRA: deficiency of interleukin-1 receptor antagonist.

experienced high blood pressure levels requiring antihypertensive therapy [65].

To the best of our knowledge, only 4 FMF patients have been treated with canakinumab in the last two years, leading in all cases to a prompt and full resolution of clinical phenotype, corroborating the concepts about efficacy of anti-IL-1 inhibition in FMF patients and suggesting that canakinumab should be considered as a potent alternative option for refractory colchicine-resistant $\operatorname{FMF}[56,67,68]$. No side effects were recorded in any of these cases and all of them continued colchicine. Interestingly, 1 patient who had been taking colchicine since the age of 10 , but started to have weekly attacks at 14 years, was treated with anakinra but became anakinra-resistant after nine months: this same patient surprisingly responded to canakinumab in only one week, with all laboratory parameters returning to normal [68].

With regard to rilonacept, a randomized, double-blind, single-participant alternating treatment study was recently conducted: 14 FMF patients who were unresponsive or intolerant to colchicine received rilonacept or a placebo. Rilonacept significantly reduced the number of FMF attacks and was shown to have an acceptable safety profile, implying its possible role in the treatment of colchicine-resistant FMF [69].

In conclusion, even though none of the anti-IL-1 biological agents are licensed for treatment of FMF and are generally prescribed as off-label drugs, anti-IL-1 agents currently expand the therapeutic choice for the colchicine-resistant or colchicine-intolerant subgroups of patients [55]. In particular, canakinumab can represent an alternative especially in the management of pediatric FMF patients, following its longer half-life and lower frequency of administration, which leads to a better compliance and fewer injection-site side effects. Because of the absence of data regarding long-term efficacy and prevention of amyloidosis, further studies are needed to define safety, tolerance, and side effects of anti-IL-1 agents and analyze whether progression of kidney disease in the case of amyloidosis can be stopped. Meanwhile, colchicine therapy could be continued during anti-IL-1 $\beta$ administration to prevent amyloidosis even in colchicine-resistant patients.

\section{Tumor Necrosis Factor-Associated Periodic Syndrome (TRAPS)}

Treatment of TRAPS appears to be more challenging than in other monogenic AIDs due to the considerable genetic heterogeneity and protean clinical spectrum of disease. A few patients gain symptomatic relief from high-dose NSAIDs, while colchicine or immunomodulators such as methotrexate, cyclosporine, and thalidomide produce very little benefit [70]. Inflammatory attacks are often responsive to corticosteroid administration, and patients may need increasing doses if frequent relapses occur, or even long-time administration in order to prevent flares [71, 72]. These subjects may also become prone to metasteroidal comorbidities. Furthermore, corticosteroids do not seem to provide a complete protection from the risk of developing reactive amyloidosis, as they do not normalize SAA levels in the majority of patients [73].

Data from the Eurofever project indicated that NSAIDs and corticosteroids were prescribed in 48 and 88 patients, respectively, mainly as on-demand therapy, with favorable results in the majority of cases [34]. In addition, colchicine was beneficial in 21 of 39 patients, 3 of whom had a complete response. The identification of TNFRSF1A mutations as the genetic cause of TRAPS raised the possibility that blocking TNF-even though elevated TNF is not observed in most TRAPS patients [74] - could potentially represent the primary therapeutic strategy in TRAPS. Interestingly, patients with the low-penetrance R92Q mutation seemed to respond better to NSAIDs and colchicine versus patients carrying other TNFRSF1A mutations [34]. Among biologic agents, to date, the cornerstone of TRAPS treatment has been etanercept, which has been shown to prevent inflammatory attacks and/or to allow the reduction of corticosteroid administration [72, 75-77]. Anecdotal reports describe its efficacy in the treatment of TRAPS-related reactive amyloidosis as well [78]. Bulua et al. have recently shown that although etanercept reduces symptoms and serum inflammatory markers in a dose-dependent manner, it does not completely normalize symptoms or acute-phase reactants in TRAPS patients [79]. 
In addition, long-term adherence to etanercept may be poor, and a significant number of patients may need to switch to anti-IL-1 therapy, most frequently due to the lack of efficacy and development of injection-site reactions [79]. A progressive decline in responsiveness to etanercept might occur over time in some cases $[80,81]$, and resistant patients have also been recently reported [82]. These data suggest a nonspecific anti-inflammatory action of etanercept in TRAPS [83]. Accordingly, data from the Eurofever registry showed that etanercept was beneficial in 32 out of 37 patients, even though only 11 (30\%) experienced a complete response [34].

In terms of the TNF- $\alpha$ neutralizing agents, both infliximab and adalimumab may cause paradoxical inflammatory attacks in TRAPS patients [81, 84]. Their paradoxical effect could be induced by (i) an increase in antiapoptotic activity and oversecretion of proinflammatory cytokines; (ii) more stable binding complexes with soluble TNF and their much higher binding avidity to transmembrane TNF of monoclonal antibodies than etanercept [85]; (iii) a reduced shedding infliximab-bound TNF $\alpha / \mathrm{TNF}$ receptor from the cell surface, leading to a marked increase in cytokine secretion and increased proinflammatory response [84]. For these reasons, caution is strongly advised when prescribing infliximab and adalimumab in patients with TRAPS.

In etanercept-resistant patients, IL-1 inhibitors have recently been shown to induce a stable and longer lasting effect in controlling TRAPS clinical manifestations and also to obtain a prompt normalization of acute-phase reactants in most patients. Though promising, results obtained with IL-1 antagonists are, to date, limited to few cases and must undergo further evaluation in larger cohorts of patients $[25,80,86]$. Anakinra has recently been shown to prevent disease relapses in the short term and induce a steady disease remission [25, 80]; in addition, its long-term efficacy and safety in patients with and without amyloidosis have also been confirmed [86]. Refractoriness to anakinra has been reported in a patient carrying a T50 M TNFRSF1A mutation [87]. We recently reported the first TRAPS patient successfully treated with canakinumab [88]: this patient carried a low-penetrance V95 M mutation, and canakinumab treatment was effective both in bringing about a rapid and complete resolution of clinical manifestations and in normalizing all markers of inflammation within a few weeks. Treatment was well tolerated and at the 6-month follow-up no adverse events were noted. Therefore, we concluded that canakinumab might represent a successful treatment option in the case of refractory TRAPS [88]. On the other hand, long-lasting drugs targeting IL-1 such as canakinumab and rilonacept could preclude the need for daily injections and the relative patient discomfort, which is mainly related to injection-site reactions. A recent phase-II trial conducted on 20 TRAPS patients showed that canakinumab produced a rapid and effective clinical benefit, which was maintained on continued administration: relapses, occurring at a median of 3 months after the last dose, were usually mild or moderate and resolved upon readministration [89].

Finally, since IL-6 levels may be elevated in TRAPS [74], it has been hypothesized that tocilizumab, a humanized monoclonal antibody that binds specifically to both soluble and membrane-bound IL-6 receptors and inhibits IL-6 receptormediated signaling, may be an alternative treatment option. A 52-year-old TRAPS patient resistant to etanercept and anakinra recently underwent tocilizumab administration for 6 months: this treatment aborted an evolving acute attack and prevented further inflammatory attacks; in addition, acute-phase reactants promptly decreased to normal values [90]. This case supports the notion of a prominent role for IL-6 in mediating inflammatory attacks in TRAPS, though these preliminary findings need to be confirmed. In order to prevent reactive amyloidosis, treatment of TRAPS must be followed by the persistent normalization of SAA levels. For this reason, close monitoring of SAA levels is recommended to detect their elevation, which may occur even in symptomfree patients as a reflection of the presence of subclinical inflammation [32]. In conclusion, anakinra and etanercept were assessed in cohort studies, achieving a " 2 b" quality level; their current strength of recommendation grade is " $\mathrm{B}$ ".

\section{Cryopyrin-Associated Periodic Syndromes (CAPS)}

Many NSAIDs, immunosuppressant agents and antihistamines, have been proven as generally ineffective in controlling the typical CAPS manifestations; in contrast, highdose oral corticosteroids and thalidomide have offered some modest improvement, at the price of numerous adverse side effects and metasteroidal comorbidities [91].

Consistent with CAPS' pathogenesis, which is linked to an increased inflammasome activity, uncontrolled caspase1 activity and subsequent robust production of IL- $1 \beta$ [92, 93], anti-IL-1 treatment appears as an ideal therapy both in controlling clinical manifestations and in preventing the development of systemic amyloidosis [94]. To date, three anti-IL-1 agents have been used for treatment of CAPS patients: anakinra, canakinumab, and rilonacept.

Since 2003, daily subcutaneous injections of anakinra have been reported to offer a quick positive effect on clinical and laboratory CAPS manifestations [95-99]. In a prospective study, 18 NOMID patients were selected to receive anakinra $1-2 \mathrm{mg} / \mathrm{kg} /$ daily subcutaneously. In all patients, anakinra markedly improved clinical signs and laboratory abnormalities, and magnetic resonance imaging showed improvement in cochlear and leptomeningeal lesions as compared with baseline. Withdrawal of anakinra uniformly resulted in relapse within days, but retreatment led to prompt new improvement. No patient discontinued treatment, and the most common adverse events were injection-site reactions and upper respiratory infections [100]. These results were invigorated by a retrospective review of 22 patients with CAPS, indicating that anakinra had sustained efficacy on dermatologic and articular manifestations and was well tolerated. Anakinra also resulted in resolution of AA amyloidosisassociated nephrotic syndrome in all affected patients [91]. To date there is no approval for anakinra use in CAPS patients, although it continues to be used as an off-label treatment. A bone erosion on the posterior surface of the patella combined with the progression of distal femoral overgrowth and 
endosteal thinning of both metaepiphyses has been observed in a 13-year-old boy with NOMID treated with anakinra for 6 years [101]. The main limitation of anakinra is its short half-life, which necessitates daily injections, often leading to injection-site reactions and poor patient compliance.

Canakinumab (150 mg in patients weighing more than $40 \mathrm{~kg}$ or $2 \mathrm{mg} / \mathrm{kg}$ in those weighing $15-40 \mathrm{~kg}$ ), administered once every eight weeks as a single dose via subcutaneous injection, provides a prompt and sustained clinical efficacy in CAPS patients [102-107]: it has been approved for treatment of CAPS in the USA and Europe since 2009, making it the only biological agent approved in Europe for therapeutic use in CAPS. The first open-label clinical trial for canakinumab was completed in 2008 with 7 CAPS patients and indicated that CAPS is entirely mediated by IL$1 \beta$ and that canakinumab treatment restores a physiological IL-1 $\beta$ production [102]. The first double-blind, randomized trial was completed in 2008 and established that treatment with canakinumab $150 \mathrm{mg}$ (or $2 \mathrm{mg} / \mathrm{kg}$ for children) every eight weeks was associated with a rapid remission of symptoms in the great majority of patients with CAPS [103]. More recently, 7 pediatric patients (5 children with MWS and 2 adolescents with NOMID) were enrolled in a phase II open-label study: all patients achieved a complete clinical and laboratory response within seven days after the first dose of canakinumab, $2 \mathrm{mg} / \mathrm{kg}$ or $150 \mathrm{mg}$ s.c, and responses were reinduced upon retreatment following relapse [104]. More recently, a phase III study conducted by Kuemmerle-Deschner et al. on 166 CAPS patients, including canakinumab-naive and pretreated patients from previous studies, confirmed the foregoing results, as canakinumab provided substantial disease control in children and adults across all CAPS phenotypes [105]. Similar results were obtained in a phase III study on 35 patients conducted by Koné-Paut et al. [106] and in an open-label study on 19 Japanese CAPS patients conducted by Imagawa et al. [107]. Canakinumab might induce an overall complete remission in $75 \%$ and a partial remission in $25 \%$ of patients, as emerging from the Eurofever study [34].

In 2008 rilonacept was the first Food and Drug Administration-approved biologic therapy in the USA for CAPS, specifically for FCAS and MWS, in patients having 12 years of age or older. Initially, improvement in clinical and laboratory features and good tolerability were highlighted by an open-label trial conducted on 5 patients with FCAS [108]. Later, two consecutive phase III studies including FCAS and MWS patients demonstrated that treatment with rilonacept (160 mg weekly via subcutaneous injection) provided a marked and lasting improvement of the clinical picture of CAPS and also normalized SAA levels [109]. Moreover, rilonacept therapy exhibited a generally favorable safety and tolerability profile. In study 1 , rilonacept reduced the disease activity score by $84 \%$, as compared with the $13 \%$ reduction among patients receiving placebo, and, in study 2 , rilonacept was superior to placebo in maintaining the improvement achieved with previous therapy with the same agent. Only injection-site reactions, upper respiratory tract infections, headache, arthralgia, and diarrhea were the most reported side effects on rilonacept. However, 1 patient died after developing sinusitis and meningitis, although study investigators thought that this death was unrelated to rilonacept [109]. Long-term efficacy and safety profile of rilonacept in the treatment of CAPS have recently been evaluated in a 72week open-label extension study, once again resulting in the improvement of CAPS clinical phenotype and normalization of inflammatory biomarkers. Moreover, rilonacept exhibited a generally favorable safety and tolerability profile in both adult and pediatric patients with CAPS throughout the extended treatment period [110].

According to the Eurofever Registry, among the 94 CAPS patients enrolled, 91.5\% received at least one anti-IL-1 agent. Anakinra proved to bring about a complete response in $64 \%$ of patients and a partial response in 34\% [34]. Rare side effects included local skin and anaphylactoid reactions.

In conclusion, the use of canakinumab and rilonacept in CAPS patients was assessed in randomized and controlled studies, resulting in a quality level of " $1 b$ "; their strength of recommendation grade is "A". Anakinra was assessed in a cohort study, achieving a quality level of " $2 \mathrm{~b}$ "; its strength of recommendation grade is " $\mathrm{B}$ ". In this framework, considering that pathogenesis of CAPS is mediated by IL-1 overproduction and in light of the extraordinary clinical effectiveness of anti-IL-1 agents, there is no role for the use of anti-TNF drugs in CAPS patients.

\section{Mevalonate Kinase Deficiency Syndrome (MKD)}

To date, no single therapy has been found to be effective in the totality of MKD patients. Most of these use NSAIDs during febrile attacks, proving only limited benefit [111]. However, according to the Eurofever Registry, the response to NSAIDs was complete in $13 \%$ of patients enrolled and partial in $64 \%$ [34]. In contrast, many patients benefit from corticosteroid administration, especially when given in high doses at the beginning of an attack [112]. In this case, data from the Eurofever registry showed that corticosteroids induced a complete or partial response, respectively, in $24 \%$ and $67 \%$ of patients enrolled [34]. Based on the pathophysiology of MKD, statins were thought to be useful, but, in the majority of cases, statins were ineffective in halting the disease course $[111,112]$. In addition, a small randomized controlled trial found that simvastatin decreased the number of febrile days in 5 out of 6 patients, but, clinically speaking, these results appeared quite modest [113].

Anti-IL-1 and anti-TNF- $\alpha$ agents are reasonable therapeutic alternatives for patients with MKD, as IL-1 and TNF$\alpha$ seem to play a relevant role in acute inflammatory attacks of MKD [114]. With regard to anti-IL-1 agents, the frequency and severity of fever attacks were eliminated or significantly reduced by anakinra treatment in most cases, demonstrating that most symptoms of MKD might be controlled or at least attenuated by anakinra [111, 115-118].

Recently, 8 patients with MKD and 3 patients with MA were treated with anti-IL-1-targeting drugs as firstline therapy: 5 patients received anakinra alone, 2 patients received canakinumab alone and, 4 patients started with 
anakinra and were later switched to canakinumab, in order to obtain a more convenient dosing schedule and to avoid injection-site reactions. A partial remission was obtained in 7 out of 9 patients on anakinra and 3 out of 6 patients on canakinumab; a complete clinical remission was obtained in 1 out of 9 patients on anakinra and 3 out of 6 patients on canakinumab. Moreover, the authors found that the number of febrile days during attacks decreased from five before treatment to three after anakinra and two after canakinumab. A decrease in C-reactive protein and SAA levels was also recorded. The doses of anakinra varied from 1 to $5 \mathrm{mg} / \mathrm{kg} / \mathrm{day}$, but 1 patient received anakinra on-demand the first day and for the seven days following an attack, with good results; the doses of canakinumab ranged from 2 to $7 \mathrm{mg} / \mathrm{kg}$ every eight weeks in 5 cases, but 1 patient received canakinumab at a dosage of $7 \mathrm{mg} / \mathrm{kg}$ every four weeks [119]. In another study by Bodar et al., anakinra induced a partial remission in 1 of 2 patients with MA, but there was no response in the other one. Continuous treatment in $1 \mathrm{MKD}$ patient induced a complete remission for seven months but was stopped due to side effects. Eight patients with MKD received anakinra ondemand, resulting in a substantial clinical response $(\geq 50 \%$ reduction in the duration of febrile attacks) with no change in attack frequency [120].

Anti-TNF treatment may also be an effective treatment choice for MKD patients, leading to improvement of both attacks and acute-phase response [121, 122]. However, a complete response to this drug is not always reported [111, 112]. Etanercept is the most used anti-TNF agent, although a small number of patients have been also treated with infliximab and adalimumab with inconsistent results [111, 123]. According to the Eurofever registry, anakinra was effective in $89 \%$ of patients, inducing a complete remission in 22\%. Etanercept was effective in $65 \%$ of patients, with only 1 complete response [34]. In contrast, Shendi et al. reported a case of a 10-year-old girl who experienced prolonged and severe inflammatory attacks when treated with etanercept and later with anakinra [124]. To sum up, biological treatments may be a promising therapeutic approach for patients with MKD, but further studies are required to confirm their beneficial clinical response or establish their long-term efficacy.

\section{NLRP12-Associated Autoinflammatory Disease (NLRP12AD)}

Currently, NLRP12AD treatment is mainly empirical: corticosteroids and antihistamines administered during the winter may lead to a clinical response, thus resulting in the control of clinical manifestations, but also a beneficial effect of NSAIDs has been reported $[125,126]$. Recently, 2 patients with NLRP12AD underwent anakinra administration and initially showed a marked clinical improvement; however, a progressive clinical relapse occurred over time, and anakinra treatment was discontinued after 14 months [127]. The authors identified the mechanism responsible for anakinra resistance in the homeostatic cytokine system, since the initial anakinra-induced IL-1 down-modulation was partially counterbalanced by an increase in TNF- $\alpha$ serum level, which could in turn circumvent the action of anakinra and eventually lead to the reactivation of IL-1 hypersecretion [127]. Nevertheless, since the crucial role of IL-1 in the pathophysiology of NLRP12AD has been demonstrated, IL-1 blockade continues to be a possible therapeutic choice [127]. In addition, based on the marked increase of serum TNF- $\alpha$ and IL-6 levels observed in 2 NLRP12AD patients treated with anakinra, anti-TNF- $\alpha$ and anti-IL- 6 agents could represent a further therapeutic approach [127].

\section{Blau Syndrome (BS)}

No studies are available about the optimal treatment for patients with BS, due to its rarity and heterogeneity in severity and evolution of its expression. The main target is to prevent ocular manifestations, which may be especially severe [128, 129]. On-demand NSAIDs can be effective for pain control, but they have limited efficacy in the prevention of disease progression [130]. Generally, low-dose glucocorticoids can maintain the quiescent stage, but high-dose corticosteroids are necessary in acute flares [131]. Corticosteroid long-term use can become problematical when a maintenance dose of prednisolone $\geq 10 \mathrm{mg}$ /day is needed for prolonged periods, and patients become prone to metasteroidal comorbidities. In these cases and in corticosteroid-resistant patients treatment with immunosuppressive drugs, such as methotrexate or azathioprine, should be tried. Bupropion was also considered for treatment of BS in the past [132]. If the response to treatment with prednisolone combined with immunosuppressant agents fails to bring about an adequate clinical remission of the disease, a TNF- $\alpha$ inhibitor should be added, such as infliximab (5-10 mg/kg every four-six weeks) $[133,134]$, although an infliximab-resistant patient has been reported [135]. Interestingly, etanercept and adalimumab do not appear to have a similar beneficial effect on the disease [133-138]. In addition, a pediatric patient with BS and etanercept-induced myelopathy has recently been described [136].

A further promising therapeutic approach may be related to anti-IL-1 agents. Anakinra in combination with mycophenolate mofetil has been proven to induce both a clear improvement in inflammatory symptoms and normalization of plasma cytokine levels in 1 BS patient [139], although it was ineffective in other cases [135]. Moreover, a recent in vitro study suggests that BS is not a disease primarily mediated by excessive IL- $1 \beta$ or other IL- 1 direct activity [135]. Nevertheless, more recently a 4 -year-old boy diagnosed with BS and suffering from a drug-resistant panuveitis underwent canakinumab administration: soon after the initiation of canakinumab, inflammatory eye signs subsided, and corticosteroid pulse treatment, which had been almost continuous for the previous 6 months, was no longer needed. The same patient showed high expression levels of innate immunity-related genes before starting anti-IL-1 suppression, and almost all of the upregulated transcripts normalized after the first canakinumab injection, suggesting that BS activity might be sustained by abnormal IL-1 production [140]. Finally, a pilot study highlighted the ability of thalidomide to 


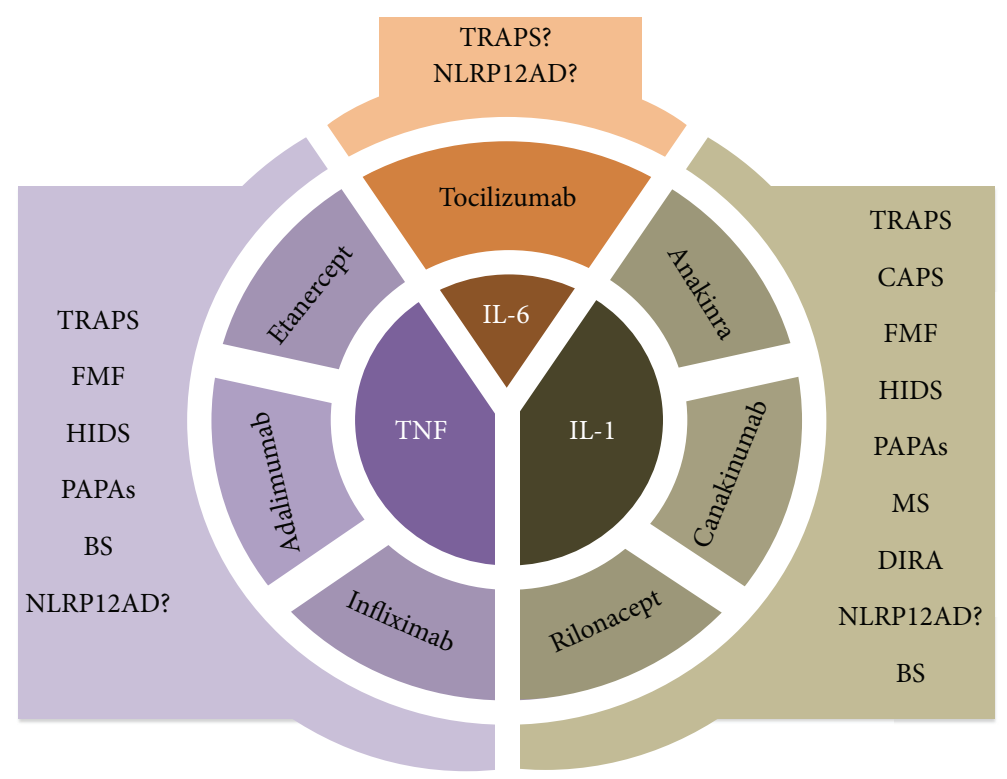

FIGURE 2: Schematic representation of the biologic agents used in the management of monogenic autoinflammatory disorders. FMF: familial Mediterranean fever; TRAPS: tumor necrosis factor receptor-associated periodic syndrome; CAPS: Cryopyrin-associated periodic syndromes; MKD: mevalonate kinase deficiency syndrome; NLRP12AD: NLRP12-associated autoinflammatory disorder; BS: Blau syndrome; MS: Majeed syndrome; PAPAs: pyogenic arthritis, pyoderma gangrenosum and acne syndrome; DIRA: deficiency of interleukin-1 receptor antagonist.

improve clinical symptoms and laboratory findings in 2 BS patients, indicating also a contributing role for NF- $\kappa$ B in BS pathogenesis [141].

\section{Majeed Syndrome (MS)}

Because of the rarity of MS, treatment is empirical. NSAIDs can provide moderate improvement, and corticosteroids are useful in controlling chronic recurrent multifocal osteomyelitis and skin manifestations, but their long-term use in children is limited by metasteroidal comorbidities. In addition, long-term outcome with this strategy has been poor, with marked failure to thrive and permanent joint deformities [10, 142-145]. Recently, Herlin et al. reported a dramatic clinical, laboratory, and radiological improvement with either anakinra or canakinumab in 2 brothers with MS, opening up a new promising therapeutic avenue. Interestingly, in these same 2 patients, the TNF- $\alpha$ inhibitor etanercept brought about no improvement, providing new insights about the pathogenesis of MS [146].

\section{Pyogenic Arthritis Pyoderma Gangrenosum and Acne Syndrome (PAPAs)}

PAPAs generally responds only slowly and partially to systemic corticosteroids, which seem to be beneficial for arthritis but less effective in pyoderma gangrenosum [147, 148]. Immunosuppressive therapies, such as cyclosporine, might lead at least to a partial response, while early treatment with sulfasalazine or leflunomide has induced remission in 1 case $[11,147]$. As regards anti-TNF $\alpha$ agents, the results are inconsistent: infliximab led to a good response in 3 cases but only a poor response in another patient $[148,149]$; etanercept induced a complete remission in 2 out of 4 reported patients [148-151]; adalimumab determined a good response in 3 patients $[148,152]$. Since PAPAs has been associated with elevated IL-1 $\beta$ production [153], targeted therapy with antiIL-1 agents has been initiated in several PAPAs patients but unfortunately with inconclusive results. Anakinra was completely effective in 3 out of 9 evaluated cases [154-156]. In another case, anakinra initially brought good results but was discontinued due to multiple infections [148]. The same authors described another patient with PAPAs who was only minimally responsive to anakinra [148]. Preliminary data on the response to anakinra administered over several months of 2 other patients was considered encouraging by Shoham et al. [153], but 2 other ones were completely unresponsive to anakinra administration $[148,149]$. Recently, a patient carrying a p.Gly258Ala mutation in the PSTPIP1 gene, diagnosed as having features of a PAPA-like syndrome, was treated with canakinumab, which led to the rapid remission of clinical signs [157]. Finally, to date, all these mentioned biologic agents have a quality level of " 4 " and a strength of recommendation grade "C" for PAPAs treatment.

\section{Deficiency of IL-1 Receptor Antagonist (DIRA)}

Patients with DIRA respond only partially to high doses of corticosteroids. However, since endogenous IL-1 receptor antagonist is lacking, DIRA patients show a prompt and sustained response to the substitutive treatment with the recombinant IL-1 receptor antagonist anakinra [12, 158-163]. 
In particular, anakinra was completely effective in 12 out of 14 cases at the dosage of $1-5 \mathrm{mg} / \mathrm{kg} /$ day and partially effective in 2 other patients who showed a good clinical response, without reaching a normalized level of acute-phase reactants. Interestingly, these 2 partially-responder patients presented a homozygous deletion of approximately $175 \mathrm{~Kb}$ on the chromosome 2q, that included ILIRN and five other genes from a cluster of IL-1-related genes, possibly explaining the reduced efficacy of anakinra [12, 164]. However, other patients carrying this deletion have recently been described as completely responsive to anakinra administration $[160,162$, 163]. To date, anakinra has a quality level of " $1 c$ " and a strength of recommendation grade "A" for treatment of DIRA.

\section{Conclusive Remarks}

Due to their hereditary nature, most of monogenic AIDs have an early onset, ranging from the first hours to the first decades of life, but different numbers of patients experience a disease onset during adulthood or go undiagnosed for long periods of time, with recurrent inflammatory symptoms of variable severity remaining misunderstood and bringing a high risk of long-term complications. Even if nowadays there is much more awareness of these disorders, the extreme rarity and relatively recent identification of most monogenic AIDs often result in a delayed diagnosis. Figure 2 shows a schematic representation of the biologic agents used in the management of the different monogenic AIDs and discussed in this review. The use of biologics requires and dictates that diagnostic times must be anticipated in these disorders, in order to alleviate or suppress many complex clinical phenotypes and avoid the occurrence of secondary amyloidosis. Large scale comparative studies between different monogenic AIDs are needed to establish the best tailored treatment strategy, but probably it will be necessary to translate all discoveries on the immunopathology of these conditions into more effective therapies. In addition, several nonhereditary multifactorial inflammatory diseases presenting clinical similarities with monogenic AIDs and having a hypothetical autoinflammatory pathogenesis might also be managed with a biologic therapeutic approach, opening new perspectives in the battlefield of medicine.

\section{Authors' Contribution}

Antonio Vitale and Donato Rigante equally contributed to this paper.

\section{References}

[1] D. Rigante, "The fresco of autoinflammatory diseases from the pediatric perspective," Autoimmunity Reviews, vol. 11, no. 5, pp. 348-356, 2012.

[2] M. Sayarlioglu, A. Cefle, M. Inanc et al., "Characteristics of patients with adult-onset familial Mediterranean fever in Turkey: analysis of 401 cases," International Journal of Clinical Practice, vol. 59, no. 2, pp. 202-205, 2005.

[3] A. Livneh, P. Langevitz, D. Zemer et al., "Criteria for the diagnosis of familial Mediterranean fever," Arthritis \& Rheumatism, vol. 40, no. 10, pp. 1879-1885, 1997.
[4] C. Dodé, M. André, T. Bienvenu et al., "French Hereditary Recurrent Inflammatory Disorder Study Group. The enlarging clinical, genetic, and population spectrum of tumor necrosis factor receptor-associated periodic syndrome," Arthritis \& Rheumatism, vol. 46, pp. 2181-2188, 2002.

[5] L. Cantarini, O. M. Lucherini, B. Frediani et al., "Bridging the gap between the clinician and the patient with cryopyrinassociated periodic syndromes," International Journal of Immunopathology and Pharmacology, vol. 24, no. 4, pp. 827-836, 2011.

[6] L. Lepore, G. Paloni, R. Caorsi et al., "Follow-up and quality of life of patients with cryopyrin-associated periodic syndromes treated with Anakinra," Journal of Pediatrics, vol. 157, no. 2, pp. 310-315, 2010.

[7] J. Frenkel, S. M. Houten, H. R. Waterham et al., "Clinical and molecular variability in childhood periodic fever with hyperimmunoglobulinaemia D," Rheumatology, vol. 40, no. 5, pp. 579-584, 2001.

[8] I. Jéru, G. Le Borgne, E. Cochet et al., "Identification and functional consequences of a recurrent NLRP12 missense mutation in periodic fever syndromes," Arthritis \& Rheumatism, vol. 63, no. 5, pp. 1459-1464, 2011.

[9] P. Sfriso, F. Caso, S. Tognon, P. Galozzi, A. Gava, and L. Punzi, "Blau syndrome, clinical and genetic aspects," Autoimmunity Reviews, vol. 12, pp. 44-51, 2012.

[10] P. J. Ferguson, S. Chen, M. K. Tayeh et al., "Homozygous mutations in LPIN2 are responsible for the syndrome of chronic recurrent multifocal osteomyelitis and congenital dyserythropoietic anaemia (Majeed syndrome)," Journal of Medical Genetics, vol. 42, no. 7, pp. 551-557, 2005.

[11] B. Tallon and M. Corkill, "Peculiarities of PAPA syndrome," Rheumatology, vol. 45, no. 9, pp. 1140-1143, 2006.

[12] I. Aksentijevich, S. L. Masters, P. J. Ferguson et al., "An autoinflammatory disease with deficiency of the interleukin-1receptor antagonist," New England Journal of Medicine, vol. 360, no. 23, pp. 2426-2437, 2009.

[13] L. Cantarini, O. M. Lucherini, F. Iacoponi et al., "Development and preliminary validation of a diagnostic score for identifying patients affected with adult-onset autoinflammatory disorders," International Journal of Immunopathology and Pharmacology, vol. 23, no. 4, pp. 1133-1141, 2010.

[14] L. Cantarini, F. Iacoponi, O. M. Lucherini et al., "Validation of a diagnostic score for the diagnosis of autoinflammatory diseases in adults," International Journal of Immunopathology and Pharmacology, vol. 24, no. 3, pp. 695-702, 2011.

[15] I. Muscari, F. Iacoponi, L. Cantarini et al., "The diagnostic evaluation of patients with potential adult-onset autoinflammatory disorders: our experience and review of the literature.," Autoimmunity Reviews, vol. 12, no. 1, pp. 10-13, 2012.

[16] L. Cantarini, O. M. Lucherini, A. Brucato et al., "Clues to detect tumor necrosis factor receptor-associated periodic syndrome (TRAPS) among patients with idiopathic recurrent acute pericarditis: results of a multicentre study," Clinical Research in Cardiology, vol. 101, pp. 525-531, 2012.

[17] L. Cantarini, D. Rigante, M. G. Brizi et al., "Clinical and biochemical landmarks in systemic autoinflammatory diseases," Annals of Medicine, vol. 44, pp. 664-673, 2012.

[18] D. Rigante, "The protean visage of systemic autoinflammatory syndromes: a challenge for inter-professional collaboration," European Review for Medical and Pharmacological Sciences, vol. 14, no. 1, pp. 1-18, 2010. 
[19] S. Trost and C. D. Rosé, "Myocarditis and sacroiliitis: 2 previously unrecognized manifestations of tumor necrosis factor receptor associated periodic syndrome," Journal of Rheumatology, vol. 32, no. 1, pp. 175-177, 2005.

[20] L. Cantarini, O. M. Lucherini, R. Cimaz et al., "Idiopathic recurrent pericarditis refractory to colchicine treatment can reveal tumor necrosis factor receptor-associated periodic syndrome," International Journal of Immunopathology and Pharmacology, vol. 22, no. 4, pp. 1051-1058, 2009.

[21] L. Cantarini, O. M. Lucherini, C. T. Baldari, F. Laghi Pasini, and M. Galeazzi, "Familial clustering of recurrent pericarditis may disclose tumour necrosis factor receptor-associated periodic syndrome," Clinical and Experimental Rheumatology, vol. 28, no. 3, pp. 405-407, 2010.

[22] A. Vitale, O. M. Lucherini, M. Galeazzi, B. Frediani, and L. Cantarini, "Long-term clinical course of patients carrying the Q703K mutation in the NLRP3 gene: a case series," Clinical and Experimental Rheumatology, vol. 30, pp. 943-946, 2012.

[23] L. Cantarini, M. Imazio, A. Brucato, O. M. Lucherini, and M. Galeazzi, "Innate versus acquired immune response in the pathogenesis of recurrent idiopathic pericarditis," Autoimmunity Reviews, vol. 9, no. 6, pp. 436-440, 2010.

[24] L. Cantarini, O. M. Lucherini, R. Cimaz, C. T. Baldari, F. Laghi Pasini, and M. Galeazzi, "Sacroileitis and pericarditis: atypical presentation of tumour necrosis factor receptor-associated periodic syndrome and response to etanercept therapy," Clinical and Experimental Rheumatology, vol. 28, no. 2, pp. 290-291, 2010.

[25] L. Cantarini, O. M. Lucherini, R. Cimaz, and M. Galeazzi, "Recurrent pericarditis caused by a rare mutation in the TNFRSF1A gene and with excellent response to anakinra treatment," Clinical and Experimental Rheumatology, vol. 28, no. 5, article 802, 2010.

[26] M. F. McDermott and I. Aksentijevich, "The autoinflammatory syndromes," Current Opinion in Allergy and Clinical Immunology, vol. 2, pp. 511-516, 2002.

[27] K. Stankovic and G. Grateau, "Auto inflammatory syndromes: diagnosis and treatment," Joint Bone Spine, vol. 74, no. 6, pp. 544-550, 2007.

[28] D. Rigante and E. Capoluongo, "The plodding diagnosis of monogenic autoinflammatory diseases in childhood: from the clinical scenery to laboratory investigation," Clinical Chemistry and Laboratory Medicine, vol. 49, no. 5, pp. 783-791, 2011.

[29] G. F. Hoffmann, C. Charpentier, E. Mayatepek et al., "Clinical and biochemical phenotype in 11 patients with mevalonic aciduria," Pediatrics, vol. 91, no. 5 I, pp. 915-921, 1993.

[30] C. Cerquaglia, M. Diaco, G. Nucera, M. La Regina, M. Montalto, and R. Manna, "Pharmacological and clinical basis of treatment of Familial Mediterranean Fever (FMF) with colchicine or analogues: an update," Current Drug Targets: Inflammation and Allergy, vol. 4, no. 1, pp. 117-124, 2005.

[31] D. Rigante, I. La Torraca, L. Avallone, A. L. Pugliese, S. Gaspari, and A. Stabile, "The pharmacologic basis of treatment with colchicine in children with familial Mediterranean fever," European Review for Medical and Pharmacological Sciences, vol. 10, no. 4, pp. 173-178, 2006.

[32] L. Obici and G. Merlini, "Amyloidosis in autoinflammatory syndromes," Autoimmunity Reviews, vol. 12, pp. 14-17, 2012.

[33] S. Savic, L. J. Dickie, M. Wittmann, and M. F. McDermott, "Autoinflammatory syndromes and cellular responses to stress: pathophysiology, diagnosis and new treatment perspectives,"
Best Practice \& Research Clinical Rheumatology, vol. 26, no. 4, pp. 505-533, 2012.

[34] N. ter Haar, H. Lachmann, S. Ozen et al., “Treatment of autoinflammatory diseases: results from the Eurofever Registry and a literature review," Annals of the Rheumatic Diseases, vol. 72, no. 5, pp. 678-685, 2013.

[35] S. E. Goldfinger, "Colchicine for familial Mediterranean fever," New England Journal of Medicine, vol. 287, no. 25, p. 1302, 1972.

[36] A. Bakkaloglu, "Familial Mediterranean fever," Pediatric Nephrology, vol. 18, no. 9, pp. 853-859, 2003.

[37] A. Aybal Kutlugun, T. Yildirim, M. Altindal, M. Arici, Ü. Yasavul, and Ç. Turgan, "AA type renal amyloidosis secondary to FMF: a long-term follow-up in two patients," Renal Failure, vol. 32, no. 10, pp. 1230-1232, 2010.

[38] N. Ozkaya and F. Yalcinkaya, "Colchicine treatment in children with familial Mediterranean fever," Clinical Rheumatology, vol. 22, pp. 314-317, 2003.

[39] D. Zemer, M. Pras, and E. Sohar, "Colchicine in the prevention and treatment of the amyloidosis of familial Mediterranean fever," New England Journal of Medicine, vol. 314, no. 16, pp. 1001-1005, 1986.

[40] G. Twig, A. Livneh, A. Vivante et al., "Mortality risk factors associated with familial Mediterranean fever among a cohort of 1.25 million adolescents," Annals of the Rheumatic Diseases. In press.

[41] E. Erken, H. T. E. Ozer, B. Bozkurt, R. Gunesacar, E. G. Erken, and S. Dinkci, "Early suppression of familial Mediterranean fever attacks by single medium dose methyl-prednisolone infusion," Joint Bone Spine, vol. 75, no. 3, pp. 370-372, 2008.

[42] P. Langevitz, D. Zemer, and A. Livneh, "Protracted febrile myalgia in patients with familial mediterranean fever," Journal of Rheumatology, vol. 21, no. 9, pp. 1708-1709, 1994.

[43] E. Seyahi, H. Ozdogan, S. Celik, S. Ugurlu, and H. Yazici, "Treatment options in colchicine resistant familial Mediterranean fever patients: thalidomide and etanercept as adjunctive agents," Clinical and Experimental Rheumatology, vol. 24, no. 5, pp. S99S103, 2006.

[44] S. Ozgocmen, L. Özçakar, O. Ardicoglu, E. Kocakoc, A. Kaya, and A. Kiris, "Familial Mediterranean fever responds well to infliximab: single case experience," Clinical Rheumatology, vol. 25, no. 1, pp. 83-87, 2006.

[45] A. Nakamura, M. Matsuda, K.-I. Tazawa, Y. Shimojima, and S.I. Ikeda, "Successful treatment with infliximab and low-dose methotrexate in a Japanese patient with familial Mediterranean fever," Internal Medicine, vol. 46, no. 15, pp. 1247-1249, 2007.

[46] A. Mor, M. H. Pillinger, M. Kishimoto, A. M. Abeles, and A. Livneh, "Familial mediterranean fever successfully treated with etanercept," Journal of Clinical Rheumatology, vol. 13, no. 1, pp. 38-40, 2007.

[47] S. Metyas, D. G. Arkfeld, D. M. Forrester, and G. R. Ehresmann, "Infliximab treatment of familial Mediterranean fever and its effect on secondary AA amyloidosis," Journal of Clinical Rheumatology, vol. 10, no. 3, pp. 134-137, 2004.

[48] H. Bodur, U. Seçkin, F. Eser, G. Ergül, and S. Seçkin, "Coexistence of familial Mediterranean fever and psoriasis in a patient with seronegative spondyloarthropathy.," Rheumatology International, vol. 29, pp. 107-110, 2008.

[49] S. Erten, S. F. Erten, and A. Altunoglu, "Successful treatment with anti-tumor necrosis factor (anti-TNF)-alpha of proteinuria in a patient with familial mediterranean fever (FMF) resistant to colchicine: anti-TNF drugs and FMF," Rheumatology International, vol. 32, pp. 1095-1097, 2011. 
[50] S. Ozgocmen and O. Akgul, "Anti-TNF agents in familial Mediterranean fever: report of three cases and review of the literature," Modern Rheumatology, vol. 21, no. 6, pp. 684-690, 2011.

[51] Z. B. Özçakar, S. Yüksel, M. Ekim, and F. Yalçınkaya, "Infliximab therapy for familial Mediterranean fever-related amyloidosis: case series with long term follow-up," Clinical Rheumatology, vol. 31, pp. 1267-1271, 2012.

[52] T. Takahashi, H. Tsukuda, H. Itoh, H. Kimura, M. Yoshimoto, and M. Tsujisaki, "An atypical familial Mediterranean fever patient who developed ulcers in the terminal ileum and recurrent abscess-like lesions in multiple organs," Internal Medicine, vol. 51, pp. 2239-2244, 2012.

[53] J. G. Ryan, S. L. Masters, M. G. Booty et al., "Clinical features and functional significance of the P369S/R408Q variant in pyrin, the familial Mediterranean fever protein," Annals of the Rheumatic Diseases, vol. 69, no. 7, pp. 1383-1388, 2010.

[54] S. Özen, Y. Bilginer, N. A. Ayaz, and M. Calguneri, "Antiinterleukin 1 treatment for patients with familial Mediterranean fever resistant to colchicine," Journal of Rheumatology, vol. 38, no. 3, pp. 516-518, 2011.

[55] L. Cantarini, N. Volpi, M. Galeazzi et al., "Colchicine myopathy and neuromyopathy: two cases with different characteristics," Journal of Clinical Rheumatology, vol. 16, no. 5, pp. 229-232, 2010.

[56] U. Meinzer, P. Quartier, J.-F. Alexandra, V. Hentgen, F. Retornaz, and I. Koné-Paut, "Interleukin-1 targeting drugs in familial mediterranean fever: a case series and a review of the literature," Seminars in Arthritis and Rheumatism, vol. 41, no. 2, pp. 265271, 2011.

[57] J. J. Chae, I. Aksentijevich, and D. L. Kastner, "Advances in the understanding of familial Mediterranean fever and possibilities for targeted therapy," British Journal of Haematology, vol. 146, no. 5, pp. 467-478, 2009.

[58] A. Soriano, E. Verecchia, A. Afeltra, R. Landolfi, and R. Manna, "IL-1 $\beta$ biological treatment of familial Mediterranean fever," Clinical Reviews in Allergy \& Immunology, 2013.

[59] J. J. Chae, G. Wood, S. L. Masters et al., "The B30.2 domain of pyrin, the familial mediterranean fever protein, interacts directly with caspase- 1 to modulate IL- $1 \beta$ production," Proceedings of the National Academy of Sciences of the United States of America, vol. 103, no. 26, pp. 9982-9987, 2006.

[60] K. Stankovic Stojanovic, Y. Delmas, P. U. Torres et al., "Dramatic beneficial effect of interleukin-1 inhibitor treatment in patients with familial Mediterranean fever complicated with amyloidosis and renal failure," Nephrology Dialysis Transplantation, vol. 27, pp. 1898-1901, 2012.

[61] Y. Bilginer, N. A. Ayaz, and S. Ozen, "Anti-IL-1 treatment for secondary amyloidosis in an adolescent with FMF and Behçet's disease," Clinical Rheumatology, vol. 29, no. 2, pp. 209-210, 2010.

[62] I. Mitroulis, V. P. Papadopoulos, T. Konstantinidis, and K. Ritis, "Anakinra suppresses familial Mediterranean fever crises in a colchicine-resistant patient," Netherlands Journal of Medicine, vol. 66, no. 11, pp. 489-491, 2008.

[63] C. Moser, G. Pohl, I. Haslinger et al., "Successful treatment of familial Mediterranean fever with Anakinra and outcome after renal transplantation," Nephrology Dialysis Transplantation, vol. 24, no. 2, pp. 676-678, 2009.

[64] R. Gattringer, H. Lagler, K. B. Gattringer et al., "Anakinra in two adolescent female patients suffering from colchicine-resistant familial Mediterranean fever: effective but risky," European Journal of Clinical Investigation, vol. 37, no. 11, pp. 912-914, 2007.
[65] R. Belkhir, L. Moulonguet-Doleris, E. Hachulla, J. Prinseau, A. Baglin, and T. Hanslik, "Treatment of familial mediterranean fever with anakinra," Annals of Internal Medicine, vol. 146, no. 11, pp. 825-826, 2007.

[66] N. Alpay, A. Sumnu, Y. Calışkan, H. Yazıcı, A. Türkmen, and A. Gül, "Efficacy of anakinra treatment in a patient with colchicine resistant familial Mediterranean fever," Rheumatology International, vol. 32, pp. 3277-3279, 2012.

[67] I. Mitroulis, P. Skendros, A. Oikonomou, A. G. Tzioufas, and K. Ritis, "The efficacy of canakinumab in the treatment of a patient with familial Mediterranean fever and longstanding destructive arthritis," Annals of the Rheumatic Diseases, vol. 70, no. 7, pp. 1347-1348, 2011.

[68] D. O. Hacihamdioglu and S. Ozen, "Canakinumab induces remission in a patient with resistant familial Mediterranean fever," Rheumatology, vol. 51, article 1041, 2012.

[69] P. J. Hashkes, S. J. Spalding, E. H. Giannini et al., "Rilonacept for colchicine-resistant or -intolerant familial Mediterranean fever: a randomized trial," Annals of Internal Medicine, vol. 157, pp. 533-541, 2012.

[70] K. M. Hull, E. Drewe, I. Aksentijevich et al., "The TNF receptorassociated periodic syndrome (TRAPS): emerging concepts of an autoinflammatory disorder," Medicine, vol. 81, no. 5, pp. 349368, 2002.

[71] M. F. McDermott, I. Aksentijevich, J. Galon et al., "Germline mutations in the extracellular domains of the $55 \mathrm{kDa}$ TNF receptor, TNFR1, define a family of dominantly inherited autoinflammatory syndromes," Cell, vol. 97, no. 1, pp. 133-144, 1999.

[72] L. Cantarini, D. Rigante, O. M. Lucherini et al., "Role of etanercept in the treatment of tumor necrosis factor receptorassociated periodic syndrome: personal experience and review of the literature," International Journal of Immunopathology and Pharmacology, vol. 23, no. 3, pp. 701-707, 2010.

[73] E. Aganna, P. N. Hawkins, S. Ozen et al., "Allelic variants in genes associated with hereditary periodic fever syndromes as susceptibility factors for reactive systemic AA amyloidosis," Genes and Immunity, vol. 5, no. 4, pp. 289-293, 2004.

[74] M. L. Nowlan, E. Drewe, H. Bulsara et al., "Systemic cytokine levels and the effects of etanercept in TNF receptor-associated periodic syndrome (TRAPS) involving a C33Y mutation in TNFRSF1A," Rheumatology, vol. 45, no. 1, pp. 31-37, 2006.

[75] S. Stojanov, C. Dejaco, P. Lohse et al., "Clinical and functional characterisation of a novel TNFRSF1A c.605T > A/V173D cleavage site mutation associated with tumour necrosis factor receptor-associated periodic fever syndrome (TRAPS), cardiovascular complications and excellent response to etanercept treatment," Annals of the Rheumatic Diseases, vol. 67, no. 9, pp. 1292-1298, 2008.

[76] J. I. Aróstegui, P. Solís, A. Aldea et al., "Etanercept plus colchicine treatment in a child with tumour necrosis factor receptor-associated periodic syndrome abolishes auto-inflammatory episodes without normalising the subclinical acute phase response," European Journal of Pediatrics, vol. 164, no. 1, pp. 13-16, 2005.

[77] K. Kusuhara, T. Hoshina, M. Saito et al., "Successful treatment of a patient with tumor necrosis factor receptor-associated periodic syndrome using a half-dose of etanercept.," Pediatrics International, vol. 54, pp. 552-555, 2012.

[78] E. Drewe, M. L. Huggins, A. G. Morgan, M. J. D. Cassidy, and R. J. Powell, “Treatment of renal amyloidosis with etanercept in 
tumour necrosis factor receptor-associated periodic syndrome," Rheumatology, vol. 43, no. 11, pp. 1405-1408, 2004.

[79] A. C. Bulua, D. B. Mogul, I. Aksentijevich et al., "Efficacy of etanercept in the tumor necrosis factor receptor-associated periodic syndrome: a prospective, open-label, dose-escalation study," Arthritis \& Rheumatism, vol. 64, no. 3, pp. 908-913, 2012.

[80] M. Gattorno, M. A. Pelagatti, A. Meini et al., "Persistent efficacy of anakinra in patients with tumor necrosis factor receptorassociated periodic syndrome," Arthritis \& Rheumatism, vol. 58, no. 5, pp. 1516-1520, 2008.

[81] E. Drewe, R. J. Powell, and E. M. Mcdermott, "Comment on: failure of anti-TNF therapy in TNF receptor 1-associated periodic syndrome (TRAPS)," Rheumatology, vol. 46, no. 12, pp. 1865-1866, 2007.

[82] S. Jacobelli, M. André, J.-F. Alexandra, C. Dodé, and T. Papo, "Failure of anti-TNF therapy in TNF receptor 1-associated Periodic Syndrome (TRAPS)," Rheumatology, vol. 46, no. 7, pp. 1211-1212, 2007.

[83] L. D. Church, S. M. Churchman, P. N. Hawkins, and M. F. McDermott, "Hereditary auto-inflammatory disorders and biologics," Springer Seminars in Immunopathology, vol. 27, no. 4, pp. 494-508, 2006.

[84] B. Nedjai, G. A. Hitman, N. Quillinan et al., "Proinflammatory action of the antiinflammatory drug infliximab in tumor necrosis factor receptor-associated periodic syndrome," Arthritis \& Rheumatism, vol. 60, no. 2, pp. 619-625, 2009.

[85] B. Scallon, A. Cai, N. Solowski et al., "Binding and functional comparisons of two types of tumor necrosis factor antagonists," Journal of Pharmacology and Experimental Therapeutics, vol. 301, no. 2, pp. 418-426, 2002.

[86] L. Obici, A. Meini, M. Cattalini et al., "Favourable and sustained response to anakinra in tumour necrosis factor receptorassociated periodic syndrome (TRAPS) with or without AA amyloidosis," Annals of the Rheumatic Diseases, vol. 70, no. 8, pp. 1511-1512, 2011.

[87] N. Quillinan, G. Mannion, A. Mohammad et al., "Failure of sustained response to etanercept and refractoriness to anakinra in patients with T50M TNF-receptor-associated periodic syndrome," Annals of the Rheumatic Diseases, vol. 70, no. 9, pp. 1692-1693, 2011.

[88] M. G. Brizi, M. Galeazzi, O. M. Lucherini, L. Cantarini, and R. Cimaz, "Successful treatment of tumor necrosis factor receptorassociated periodic syndrome with canakinumab," Annals of Internal Medicine, vol. 156, no. 12, pp. 907-908, 2012.

[89] M. Gattorno, L. Obici, A. Meini et al., "Efficacy and safety of canakinumab in patients with TNF receptor associated periodic syndrome," Annals of the Rheumatic Diseases, vol. 71, supplement 3, article 289, 2012.

[90] P. M. Vaitla, P. M. Radford, P. J. Tighe et al., "Role of interleukin6 in a patient with tumor necrosis factor receptor-associated periodic syndrome," Arthritis \& Rheumatism, vol. 63, no. 4, pp. 1151-1155, 2011.

[91] K. S. Leslie, H. J. Lachmann, E. Bruning et al., "Phenotype, genotype, and sustained response to anakinra in 22 patients with autoinflammatory disease associated with CIAS-1/NALP3 mutations," Archives of Dermatology, vol. 142, no. 12, pp. 15911597, 2006.

[92] L. Agostini, F. Martinon, K. Burns, M. F. McDermott, P. N. Hawkins, and J. Tschopp, "NALP3 forms an IL-1 $\beta$-processing inflammasome with increased activity in Muckle-Wells autoinflammatory disorder," Immunity, vol. 20, no. 3, pp. 319-325, 2004.
[93] M. Gattorno, S. Tassi, S. Carta et al., "Pattern of interleukin-1 $\beta$ secretion in response to lipopolysaccharide and ATP before and after interleukin-1 blockade in patients with CIAS1 mutations," Arthritis \& Rheumatism, vol. 56, no. 9, pp. 3138-3148, 2007.

[94] J. D. Gillmore, L. B. Lovat, M. R. Persey, M. B. Pepys, and P. N. Hawkins, "Amyloid load and clinical outcome in AA amyloidosis in relation to circulating concentration of serum amyloid A protein," Lancet, vol. 358, no. 9275, pp. 24-29, 2001.

[95] P. N. Hawkins, H. J. Lachmann, and M. F. McDermott, "Interleukin-1-receptor antagonist in the Muckle-Wells syndrome," New England Journal of Medicine, vol. 348, no. 25, pp. 25832584, 2003.

[96] H. M. Hoffman, S. Rosengren, D. L. Boyle et al., "Prevention of cold-associated acute inflammation in familial cold autoinflammatory syndrome by interleukin-1 receptor antagonist," The Lancet, vol. 364, no. 9447, pp. 1779-1785, 2004.

[97] E. Ramos, J. I. Aróstegui, S. Campuzano, J. Rius, C. Bousoño, and J. Yagüe, "Positive clinical and biochemical responses to anakinra in a 3-yr-old patient with cryopyrin-associated periodic syndrome (CAPS)," Rheumatology, vol. 44, no. 8, pp. 1072-1073, 2005.

[98] D. Rigante, V. Ansuini, M. Caldarelli, B. Bertoni, I. La Torraca, and A. Stabile, "Hydrocephalus in CINCA syndrome treated with anakinra," Child's Nervous System, vol. 22, no. 4, pp. 334337, 2006.

[99] C. Boschan, O. Witt, P. Lohse, I. Foeldvari, H. Zappel, and L. Schweigerer, "Neonatal-onset multisystem inflammatory disease (NOMID) due to a novel S331R mutation of the CIAS1 gene and response to interleukin-1 receptor antagonist treatment," American Journal of Medical Genetics, vol. 140, no. 8, pp. 883886, 2006.

[100] R. Goldbach-Mansky, N. J. Dailey, S. W. Canna et al., "Neonatal-onset multisystem inflammatory disease responsive to interleukin-1 $\beta$ inhibition," New England Journal of Medicine, vol. 355, no. 6, pp. 581-592, 2006.

[101] D. Rigante, A. Leone, R. Marrocco, M. E. Laino, and A. Stabile, "Long-term response after 6-year treatment with anakinra and onset of focal bone erosion in neonatal-onset multisystem inflammatory disease (NOMID/CINCA)," Rheumatology International, vol. 31, no. 12, pp. 1661-1664, 2011.

[102] H. J. Lachmann, P. Lowe, S. D. Felix et al., "In vivo regulation of interleukin $1 \beta$ in patients with cryopyrin-associated periodic syndromes," Journal of Experimental Medicine, vol. 206, no. 5, pp. 1029-1036, 2009.

[103] H. J. Lachmann, I. Kone-Paut, J. B. Kuemmerle-Deschner et al., "Use of canakinumab in the cryopyrin-associated periodic syndrome," New England Journal of Medicine, vol. 360, no. 23, pp. 2416-2425, 2009.

[104] J. B. Kuemmerle-Deschner, E. Ramos, N. Blank et al., "Canakinumab (ACZ885, a fully human IgG1 anti-IL-1 $\beta \mathrm{mAb}$ ) induces sustained remission in pediatric patients with cryopyrin-associated periodic syndrome (CAPS)," Arthritis Research and Therapy, vol. 13, no. 1, article R34, 2011.

[105] J. B. Kuemmerle-Deschner, E. Hachulla, R. Cartwright et al., "Two-year results from an open-label, multicentre, phase III study evaluating the safety and efficacy of canakinumab in patients with cryopyrin-associated periodic syndrome across different severity phenotypes," Annals of the Rheumatic Diseases, vol. 70, no. 12, pp. 2095-2102, 2011.

[106] I. Koné-Paut, H. J. Lachmann, J. B. Kuemmerle-Deschner et al., "Sustained remission of symptoms and improved health-related quality of life in patients with cryopyrin-associated periodic 
syndrome treated with canakinumab: Results of a double-blind placebo-controlled randomized withdrawal study," Arthritis Research and Therapy, vol. 13, no. 6, article R202, 2011.

[107] T. Imagawa, R. Nishikomori, H. Takada et al., "Safety and efficacy of canakinumab in Japanese patients with phenotypes of cryopyrin-associated periodic syndrome as established in the first open-label, phase-3 pivotal study (24-week results)," Clinical and Experimental Rheumatology, vol. 31, pp. 302-309, 2013.

[108] R. Goldbach-Mansky, S. D. Shroff, M. Wilson et al., "A pilot study to evaluate the safety and efficacy of the long-acting interleukin-1 inhibitor rilonacept (Interleukin-1 Trap) in patients with familial cold autoinflammatory syndrome," Arthritis \& Rheumatism, vol. 58, no. 8, pp. 2432-2442, 2008.

[109] H. M. Hoffman, M. L. Throne, N. J. Amar et al., "Efficacy and safety of rilonacept (Interleukin-1 Trap) in patients with cryopyrin-associated periodic syndromes: results from two sequential placebo-controlled studies," Arthritis \& Rheumatism, vol. 58, no. 8, pp. 2443-2452, 2008.

[110] H. M. Hoffman, M. L. Throne, N. J. Amar et al., "Long-term efficacy and safety profile of rilonacept in the treatment of cryopryin-associated periodic syndromes: results of a 72-week open-label extension study," Clinical Therapeutics, vol. 34, pp. 2091-2103, 2012.

[111] B. Bader-Meunier, B. Florkin, J. Sibilia et al., "Mevalonate kinase deficiency: a survey of 50 patients," Pediatrics, vol. 128, no. 1, pp. e152-e159, 2011.

[112] J. C. H. van der Hilst, E. J. Bodar, K. S. Barron et al., "Longterm follow-up, clinical features, and quality of life in a series of 103 patients with hyperimmunoglobulinemia D syndrome," Medicine, vol. 87, no. 6, pp. 301-310, 2008.

[113] A. Simon, E. Drewe, J. W. M. van der Meer et al., "Simvastatin treatment for inflammatory attacks of the hyperimmunoglobulinemia D and periodic fever syndrome," Clinical Pharmacology and Therapeutics, vol. 75, no. 5, pp. 476-483, 2004.

[114] J. P. H. Drenth, M. van Deuren, J. van der Ven-Jongekrijg, C. G. Schalkwijk, and J. W. M. van der Meer, "Cytokine activation during attacks of the hyperimmunoglobulinemia $\mathrm{D}$ and periodic fever syndrome," Blood, vol. 85, no. 12, pp. 3586-3593, 1995.

[115] M. Cailliez, F. Garaix, C. Rousset-Rouvière et al., "Anakinra is safe and effective in controlling hyperimmunoglobulinaemia D syndrome-associated febrile crisis," Journal of Inherited Metabolic Disease, vol. 29, no. 6, p. 763, 2006.

[116] B. Neven, V. Valayannopoulos, P. Quartier et al., "Allogeneic bone marrow transplantation in mevalonic aciduria," New England Journal of Medicine, vol. 356, no. 26, pp. 2700-2703, 2007.

[117] D. Rigante, V. Ansuini, B. Bertoni et al., "Treatment with anakinra in the hyperimmunoglobulinemia D/periodic fever syndrome," Rheumatology International, vol. 27, no. 1, pp. 97100, 2006.

[118] M. Korppi, M. E. van Gijn, and K. Antila, "Hyperimmunoglobulinemia D and periodic fever syndrome in children. Review on therapy with biological drugs and case report," Acta Paediatrica, International Journal of Paediatrics, vol. 100, no. 1, pp. 21-25, 2011.

[119] C. Galeotti, U. Meinzer, P. Quartier et al., "Efficacy of interleukin-1-targeting drugs in mevalonate kinase deficiency," Rheumatology (Oxford), vol. 51, pp. 1855-1859, 2012.

[120] E. J. Bodar, L. M. Kuijk, J. P. H. Drenth, J. W. M. Van Der Meer, A. Simon, and J. Frenkel, "On-demand anakinra treatment is effective in mevalonate kinase deficiency," Annals of the Rheumatic Diseases, vol. 70, no. 12, pp. 2155-2158, 2011.

[121] R. Topaloğlu, N. A. Ayaz, H. R. Waterham, A. Yüce, F. Gumruk, and Ö. Sanal, "Hyperimmunoglobulinemia D and periodic fever syndrome; treatment with etanercept and follow-up," Clinical Rheumatology, vol. 27, no. 10, pp. 1317-1320, 2008.

[122] K. Takada, I. Aksentijevich, V. Mahadevan, J. A. Dean, R. I. Kelley, and D. L. Kastner, "Favorable preliminary experience with etanercept in two patients with the hyperimmunoglobulinemia $\mathrm{D}$ and periodic fever syndrome," Arthritis \& Rheumatism, vol. 48, no. 9, pp. 2645-2651, 2003.

[123] C. L. Kraus and S. M. Culican, "Nummular keratopathy in a patient with Hyper-IgD Syndrome," Pediatric Rheumatology, vol. 7, article 14, 2009.

[124] H. M. Shendi, D. Walsh, and J. D. M. Edgar, "Etanercept and anakinra can prolong febrile episodes in patients with hyperimmunoglobulin D and periodic fever syndrome," Rheumatology International, vol. 32, no. 1, pp. 249-251, 2012.

[125] S. Borghini, S. Tassi, S. Chiesa et al., "Clinical presentation and pathogenesis of cold-induced autoinflammatory disease in a family with recurrence of an NLRP12 mutation," Arthritis \& Rheumatism, vol. 63, no. 3, pp. 830-839, 2011.

[126] I. Jéru, P. Duquesnoy, T. Fernandes-Alnemri et al., "Mutations in NALP12 cause hereditary periodic fever syndromes," Proceedings of the National Academy of Sciences of the United States of America, vol. 105, no. 5, pp. 1614-1619, 2008.

[127] I. Jéru, V. Hentgen, S. Normand et al., "Role of interleukin-1 $\beta$ in NLRP12-associated autoinflammatory disorders and resistance to anti-interleukin-1 therapy," Arthritis \& Rheumatism, vol. 63, no. 7, pp. 2142-2148, 2011.

[128] T. Kurokawa, T. Kikuchi, K. Ohta, H. Imai, and N. Yoshimura, "Ocular manifestations in Blau syndrome associated with a CARD15/Nod2 mutation," Ophthalmology, vol. 110, no. 10, pp. 2040-2044, 2003.

[129] E. B. Blau, "Familial granulomatous arthritis, iritis, and rash," Journal of Pediatrics, vol. 107, no. 5, pp. 689-693, 1985.

[130] L. Punzi, A. Furlan, M. Podswiadek et al., "Clinical and genetic aspects of Blau syndrome: a 25-year follow-up of one family and a literature review," Autoimmunity Reviews, vol. 8, no. 3, pp. 228-232, 2009.

[131] P. A. Latkany, D. A. Jabs, J. R. Smith et al., "Multifocal choroiditis in patients with familial juvenile systemic granulomatosis," American Journal of Ophthalmology, vol. 134, no. 6, pp. 897-904, 2002.

[132] E. L. Altschuler and R. E. Kast, "Bupropion for Blau syndrome," Medical Hypotheses, vol. 62, no. 2, pp. 297-298, 2004.

[133] N. Milman, C. B. Andersen, A. Hansen et al., "Favourable effect of TNF- $\alpha$ inhibitor (infliximab) on Blau syndrome in monozygotic twins with a de novo CARD15 mutation," APMIS, vol. 114, no. 12, pp. 912-919, 2006.

[134] V. R. Raiji, M. M. Miller, and L. K. Jung, "Uveitis in Blau syndrome from a de novo mutation of the NOD2/CARD15 gene," Journal of AAPOS, vol. 15, no. 2, pp. 205-207, 2011.

[135] T. M. Martin, Z. Zhang, P. Kurz et al., "The NOD2 defect in Blau syndrome does not result in excess interleukin-1 activity," Arthritis \& Rheumatism, vol. 60, no. 2, pp. 611-618, 2009.

[136] F. Caracseghi, J. Izquierdo-Blasco, A. Sanchez-Montanez, S. Melendo-Perez, M. Roig-Quilis, and C. Modesto, "Etanerceptinduced myelopathy in a pediatric case of Blau syndrome," Case Reports in Rheumatology, vol. 2011, Article ID 134106, 5 pages, 2011. 
[137] I. A. Cuesta, E. C. Moore, R. Rabah, and E. V. Bawle, "Blau syndrome (familial granulomatous arthritis, iritis, and rash) in an African-American family," Journal of Clinical Rheumatology, vol. 6, no. 1, pp. 30-34, 2000.

[138] S. M. Sharma, T. M. Martin, C. D. Rosé, A. D. Dick, and A. V. Ramanan, "Distinguishing between the innate immune response due to ocular inflammation and infection in a child with juvenile systemic granulomatous disease treated with antiTNF- $\alpha$ monoclonal antibodies," Rheumatology, vol. 50, no. 5, pp. 990-992, 2011.

[139] J. I. Aróstegui, C. Arnal, R. Merino et al., "NOD2 gene-associated pediatric granulomatous arthritis: clinical diversity, novel and recurrent mutations, and evidence of clinical improvement with interleukin-1 blockade in a Spanish cohort," Arthritis \& Rheumatism, vol. 56, no. 11, pp. 3805-3813, 2007.

[140] G. Simonini, Z. Xu, R. Caputo et al., "Clinical and transcriptional response to the long-acting interleukin-1 blocker canakinumab in Blau syndrome-related uveitis," Arthritis \& Rheumatism, vol. 65, no. 2, pp. 513-518, 2013.

[141] K. Yasui, M. Yashiro, M. Tsuge et al., "Thalidomide dramatically improves the symptoms of early-onset sarcoidosis/blau syndrome: its possible action and mechanism," Arthritis \& Rheumatism, vol. 62, no. 1, pp. 250-257, 2010.

[142] H. A. Majeed, M. Kalaawi, D. Mohanty et al., "Congenital dyserythropoietic anemia and chronic recurrent multifocal osteomyelitis in three related children and the association with Sweet syndrome in two siblings," Journal of Pediatrics, vol. 115, no. 5, pp. 730-734, 1989.

[143] H. A. Majeed, M. Al-Tarawna, H. El-Shanti, B. Kamel, and F. Al-Khalaileh, "The syndrome of chronic recurrent multifocal osteomyelitis and congenital dyserythropoietic anaemia. Report of a new family and a review," European Journal of Pediatrics, vol. 160, no. 12, pp. 705-710, 2001.

[144] H. A. Majeed, H. El-Shanti, H. Al-Rimawi, and N. Al-Masri, "On mice and men: an autosomal recessive syndrome of chronic recurrent multifocal osteomyelitis and congenital dyserythropoietic anemia," Journal of Pediatrics, vol. 137, no. 3, pp. 441-442, 2000.

[145] Z. S. Al-Mosawi, K. K. Al-Saad, R. Ijadi-Maghsoodi, H. I. ElShanti, and P. J. Ferguson, "A splice site mutation confirms the role of LPIN2 in Majeed syndrome," Arthritis \& Rheumatism, vol. 56, no. 3, pp. 960-964, 2007.

[146] T. Herlin, B. Fiirgaard, M. Bjerre et al., "Efficacy of anti-IL1 treatment in Majeed syndrome," Annals of the Rheumatic Diseases, vol. 72, pp. 410-413, 2013.

[147] N. M. Llndor, T. M. Arsenault, H. Solomon, C. E. Seidman, and M. T. McEvov, "A new autosomal dominant disorder of pyogenic sterile arthritis, pyoderma gangrenosum, and acne: PAPA syndrome," Mayo Clinic Proceedings, vol. 72, no. 7, pp. 611615, 1997.

[148] A. P. Demidowich, A. F. Freeman, D. B. Kuhns et al., "Brief report: genotype, phenotype, and clinical course in five patients with PAPA syndrome (pyogenic sterile arthritis, pyoderma gangrenosum, and acne)," Arthritis \& Rheumatism, vol. 64, no. 6, pp. 2022-2027, 2012.

[149] D. S. Stichweh, M. Punaro, and V. Pascual, "Dramatic improvement of pyoderma gangrenosum with infliximab in a patient with PAPA syndrome," Pediatric Dermatology, vol. 22, no. 3, pp. 262-265, 2005.

[150] E. Cortis, F. de Benedetti, A. Insalaco et al., "Abnormal production of the tumor necrosis factor inhibitor etanercept and clinical efficacy of tumor in a patient with PAPA syndrome," Journal of Pediatrics, vol. 145, no. 6, pp. 851-855, 2004.

[151] N. D. Tofteland and T. S. Shaver, "Clinical efficacy of etanercept for treatment of PAPA syndrome," Journal of Clinical Rheumatology, vol. 16, no. 5, pp. 244-245, 2010.

[152] H. Lee, S. H. Park, S. K. Kim, J. Y. Choe, and J. S. Park, "Pyogenic arthritis, pyoderma gangrenosum, and acne syndrome (PAPA syndrome) with E250K mutation in CD2BP1 gene treated with the tumor necrosis factor inhibitor adalimumab," Clinical and Experimental Rheumatology, vol. 30, article 452, 2012.

[153] N. G. Shoham, M. Centola, E. Mansfield et al., "Pyrin binds the PSTPIP1/CD2BP1 protein, defining familial Mediterranean fever and PAPA syndrome as disorders in the same pathway," Proceedings of the National Academy of Sciences of the United States of America, vol. 100, no. 23, pp. 13501-13506, 2003.

[154] M. P. Dierselhuis, J. Frenkel, N. M. Wulffraat, and J. J. Boelens, "Anakinra for flares of pyogenic arthritis in PAPA syndrome," Rheumatology, vol. 44, no. 3, pp. 406-408, 2005.

[155] M. Brenner, T. Ruzicka, G. Plewig, P. Thomas, and P. Herzer, "Targeted treatment of pyoderma gangrenosum in PAPA (pyogenic arthritis, pyoderma gangrenosum and acne) syndrome with the recombinant human interleukin-1 receptor antagonist anakinra," British Journal of Dermatology, vol. 161, no. 5, pp. 1199-1201, 2009.

[156] M. A. Schellevis, M. Stoffels, E. P. A. H. Hoppenreijs, E. Bodar, A. Simon, and J. W. M. van der Meer, "Variable expression and treatment of PAPA syndrome," Annals of the Rheumatic Diseases, vol. 70, no. 6, pp. 1168-1170, 2011.

[157] A. Geusau, N. Mothes-Luksch, H. Nahavandi et al., "Identification of a homozygous PSTPIP1 mutation in a patient with a PAPA-like syndrome responding to canakinumab treatment," JAMA Dermatology, vol. 149, pp. 209-215, 2013.

[158] P. G. Thacker, L. A. Binkovitz, and K. B. Thomas, "Deficiency of interleukin-1-receptor antagonist syndrome: a rare autoinflammatory condition that mimics multiple classic radiographic findings," Pediatric Radiology, vol. 42, pp. 495-498, 2012.

[159] A. A. Jesus, M. Osman, C. A. Silva et al., "A novel mutation of ILIRN in the deficiency of interleukin-1 receptor antagonist syndrome: description of two unrelated cases from Brazil," Arthritis \& Rheumatism, vol. 63, no. 12, pp. 4007-4017, 2011.

[160] K. Minkis, I. Aksentijevich, R. Goldbach-Mansky et al., "Interleukin 1 receptor antagonist deficiency presenting as infantile pustulosis mimicking infantile pustular psoriasis," Archives of Dermatology, vol. 148, pp. 747-752, 2012.

[161] M. Stenerson, K. Dufendach, I. Aksentijevich, J. Brady, J. Austin, and A. M. Reed, "The first reported case of compound heterozygous IL1RN mutations causing deficiency of the interleukin-1 receptor antagonist," Arthritis \& Rheumatism, vol. 63, no. 12, pp. 4018-4022, 2011.

[162] S. Reddy, S. Jia, R. Geoffrey et al., "An autoinflammatory disease due to homozygous deletion of the ILIRN locus," New England Journal of Medicine, vol. 360, no. 23, pp. 2438-2444, 2009.

[163] C. Schnellbacher, G. Ciocca, R. Menendez et al., "Deficiency of interleukin-1 receptor antagonist responsive to Anakinra," Pediatric Dermatology, 2012.

[164] C. N. Brau-Javier, J. Gonzales-Chavez, and J. R. Toro, "Chronic cutaneous pustulosis due to a $175-\mathrm{kb}$ deletion on chromosome 2q13: excellent response to anakinra," Archives of Dermatology, vol. 148, no. 3, pp. 301-304, 2012. 


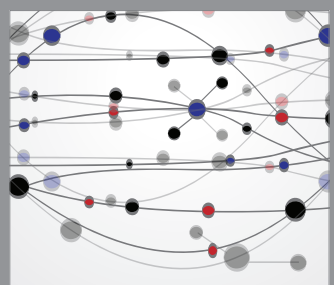

The Scientific World Journal
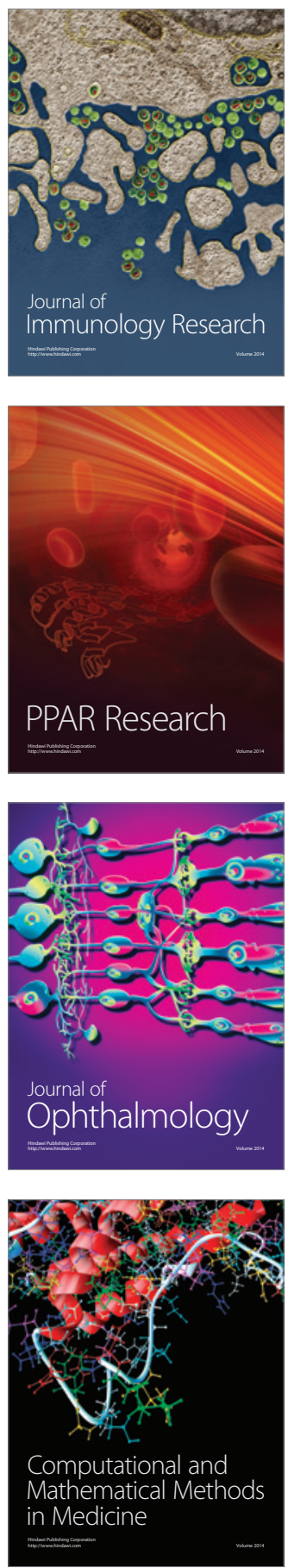

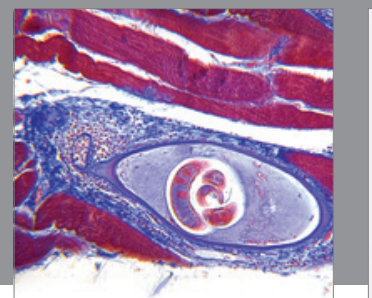

Gastroenterology

Research and Practice
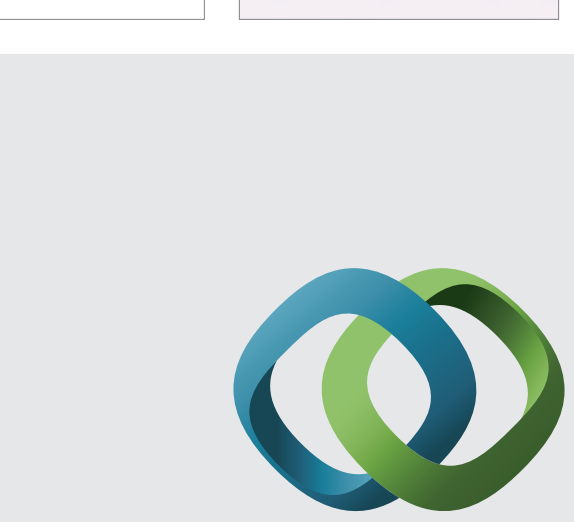

\section{Hindawi}

Submit your manuscripts at

http://www.hindawi.com
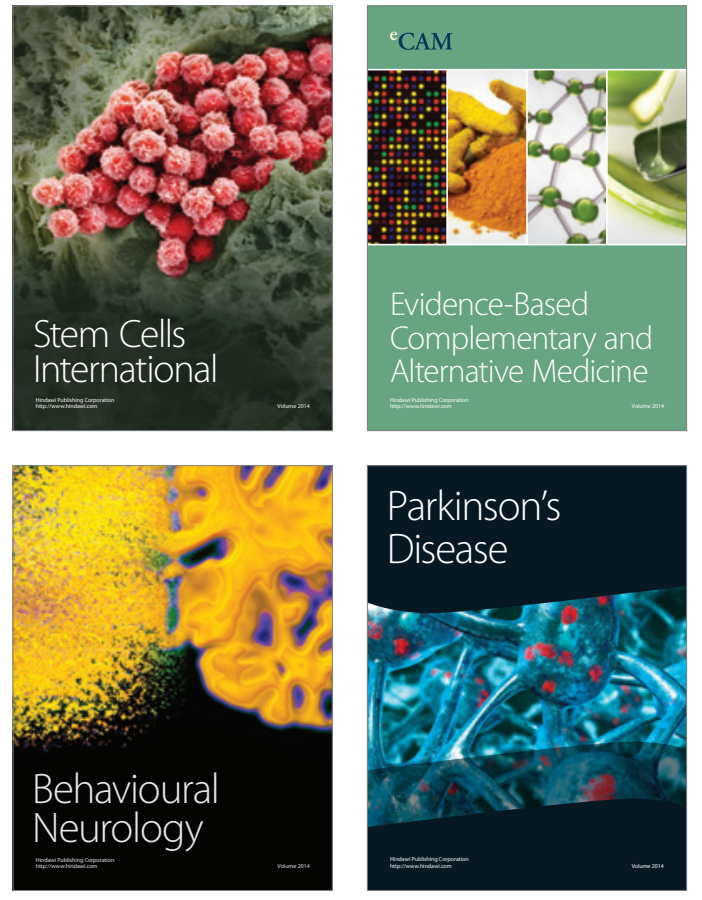
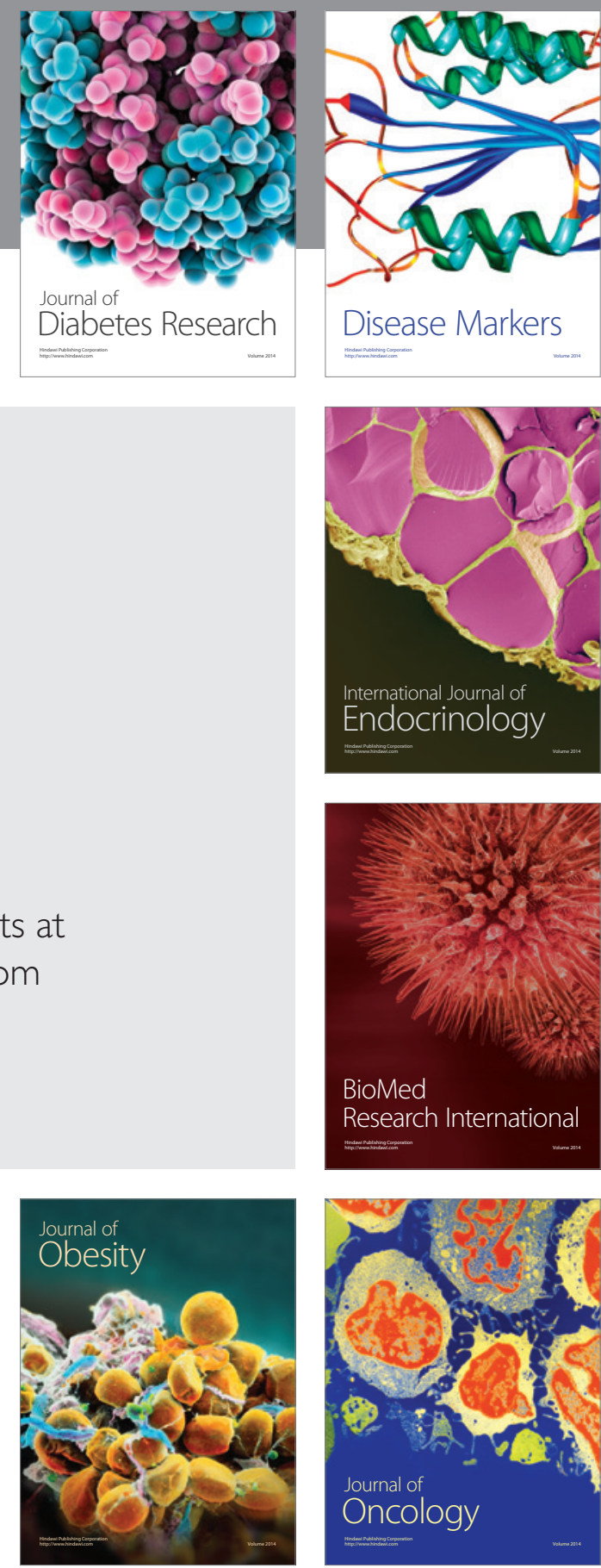

Disease Markers
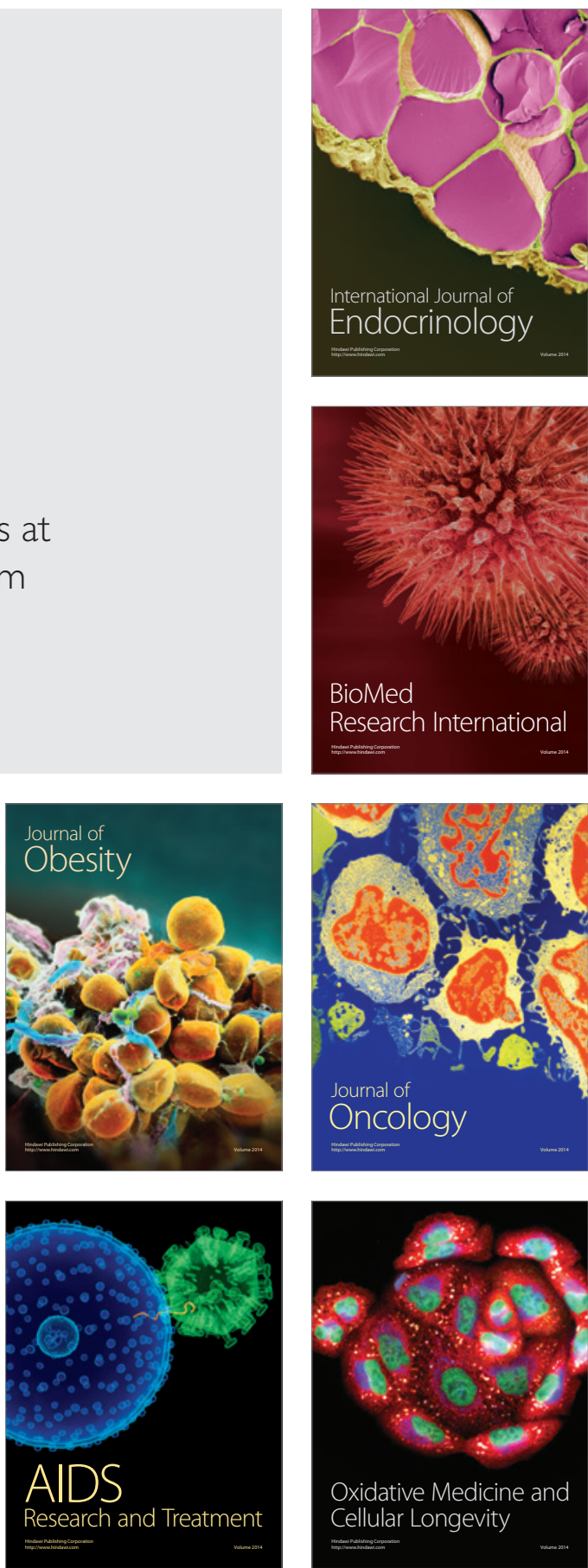